\title{
Distributed Fibre Optic Sensing of Axially Loaded Bored Piles
}

\author{
Loizos Pelecanos ${ }^{1}$, Kenichi Soga ${ }^{2}$, Mohammed Z. E. B. Elshafie ${ }^{3}$, Nicholas de Battista ${ }^{4}$, \\ Cedric Kechavarzi ${ }^{5}$, Chang Ye Gue ${ }^{6}$, Yue Ouyang ${ }^{7}$, Hyung-Joon Seo ${ }^{8}$
}

\footnotetext{
${ }^{1}$ Lecturer in Geotechnical Engineering, Department of Architecture \& Civil Engineering, University of Bath. Claverton Down, Bath, BA2 7AY, United Kingdom. Formerly: Research Associate, University of Cambridge, United Kingdom. Email: L.Pelecanos@bath.ac.uk. (Corresponding Author).

${ }^{2}$ Chancellor's Professor of Civil Engineering, Department of Civil \& Environmental Engineering, University of California, Berkeley. 760 Davis Hall, 94720-1710, United States of America. Formerly: Professor, University of Cambridge, United Kingdom. Email: Soga@berkeley.edu
}

${ }^{3}$ Lecturer in Construction Engineering, Centre for Smart Infrastructure \& Construction, Department of Engineering, University of Cambridge. Trumpington Street, Cambridge, CB2 1PZ, United Kingdom. Email: ME254@cam.ac.uk

${ }^{4}$ Research Associate, Centre for Smart Infrastructure \& Construction, Department of Engineering, University of Cambridge. Trumpington Street, Cambridge, CB2 1PZ, United Kingdom. Email: N.Debattista@eng.cam.ac.uk

${ }^{5}$ Training \& Knowledge Transfer Manager, Centre for Smart Infrastructure \& Construction, Department of Engineering, University of Cambridge. Trumpington Street, Cambridge, CB2 1PZ, United Kingdom. Email: CK209@cam.ac.uk

${ }^{6} \mathrm{PhD}$ Research Student, Centre for Smart Infrastructure \& Construction, Department of Engineering, University of Cambridge. Trumpington Street, Cambridge, CB2 1PZ, United Kingdom. Email: CYG20@cam.ac.uk

${ }^{7}$ Project Manager, Cementation Skanska. Formerly: University of Cambridge, United Kingdom. Neelands House, Pipering Lane, Doncaster, DN5 9NB, United Kingdom. Email: Echo.Ouyang@skanska.co.uk

${ }^{8}$ Lecturer, Department of Civil Engineering, Xi'an Jiaotong - Liverpool University, Shaanxi Sheng, China, 710048, China. Formerly: Research Associate, University of Cambridge, United Kingdom. Email: Hyungjoon.Seo@xjtlu.edu.cn

\begin{abstract} Instrumented pile tests are vital to establish the performance of a pile and validate the assumptions made during initial design. Conventional instrumentation includes vibrating wire strain gauges and extensometers to measure the change in strain or displacements within a pile. While these strain and displacement gauges are very accurate, they only provide strain/displacement readings at discrete locations at which they are installed. It is therefore common to interpolate between two consecutive points to obtain the values corresponding to the data gaps in between; in practice, these discrete instrumented points could be tens of
\end{abstract}


meters apart, at depths corresponding to different soil layers, and hence simple interpolation between the measurement points remains questionable. The Brillouin Optical Time Domain Reflectometry fibre optic strain sensing system however is able to provide distributed strain sensing along the entire length of the cable, enabling the full strain profile to be measured during a maintained pile load test. The strain data can also be integrated to obtain the displacement profile. In this paper, three case studies are presented where the performance of three concrete bored piles in London is investigated using both conventional vibrating wire strain gauges and distributed fibre optic strain sensing during maintained pile load tests which enabled comparisons to be made between the two instrumentation systems. In addition, finite element analyses were conducted for the three piles and it was found that the ability to measure the full strain profiles for each pile is highly advantageous in understanding the performance of the pile and in detecting any abnormalities in the pile behaviour.

Keywords: piles, field monitoring, fibre optic sensors, load transfer, pile load test, finite element analysis, pile instrumentation

\section{Introduction}

The overall geotechnical capacity of a pile is derived from the skin friction and the base resistance. The design process begins with evaluating moderately conservative soil parameters based on site investigation test results. Depending on the type of soil, different equations and methods for pile capacity can be used. For example, for piles in clay the amethod and the method proposed by Meyerhof (1965) are commonly used (e.g. in the UK) to predict the ultimate skin friction and end bearing resistance respectively. Other methods

51 adopt direct correlations based on in situ soil investigation (e.g. CPT, SPT) (Eslami \& Fellenius 1997), LCPC (Bustamante \& Gianeselli 1982), IC method (Jardine \& Chow 1996). More complex and rigorous numerical methods can also be employed for complicated pile problems such as piled groups (Kraft, Ray \& Kakaaki 1981; Poulos 1989; Randolph 2003) and piled raft (Poulos \& Davis 1974; Kitiyodom \& Matsumoto 2003) foundations.

56 Nevertheless, all of these methods are used in the design stage and therefore they only 
57 provide an estimate of a pile's behaviour. As such, instrumented pile tests are recommended 58 by standard codes of practice (e.g. clause 7.5 of Eurocode 7 ) to quantify the performance of a pile in order to validate the initial design assumptions.

60 General preliminary pile tests (McCabe \& Lehane 2006) include a number of vibrating wire 61 strain gauges (VWSG), either in pairs or threes at several levels within the pile, along with a measurement of pile head settlement measured from an independent reference beam by linear voltage distance transducers (LVDT). This instrumentation scheme offers very useful but discrete data points (Lehane et al. 1993). Data from appropriately monitored pile load tests can provide a means to assess the behaviour of the pile and develop pile behaviour models (Comodromos \& Bareka 2009) such as load transfer curves (Ménard 1963; Butterfield \& Banergee 1971; Kraft, Ray \& Kakaaki 1981; Frank \& Zhao 1982; Poulos 1989; Lee 1993; Klar et al. 2006; Abchir et al. 2015; Seo et al. 2017).

Recent advances in geotechnical instrumentation include fibre optic (FO) technology such as Fibre Bragg Gratings (FBG) (Kersey \& Morey 1993; Lee et al. 2004; Liu \& Zhang 2012; Doherty et al. 2015) and distributed Brillouin Optical Time-Domain Reflectometry (BOTDR) (Kurashima et al. 1993; Soga 2014; Pelecanos et al. 2017). The latter technology offers near spatially-continuous strain data along the entire length of the pile, which can be further processed to provide detailed information regarding the pile behaviour and integrity and load-transfer properties (Pelecanos \& Soga 2017; de Battista et al. 2016). The BOTDR technique has been successfully used to monitor various soil-structure interaction problems (Acikgoz et al. 2016; Acikgoz et al. 2017), including piles (Klar et al. 2006; Ouyang et al. 2015; Pelecanos et al. 2016), shafts/retaining walls (Mohamad et al. 2011; Schwamb et al. 2014; Schwamb \& Soga 2015), tunnel linings (Mohamad et al. 2010; Mohamad et al. 2012; Cheung et al. 2010; de Battista et al. 2015; Di Murro et al. 2016; Soga et al. 2017), tunnelling and other geotechnical process-induced surface settlements (Hauswirth et al. 2014; Klar,

82 Dromy \& Linker 2014; Linker \& Klar 2015), concrete cracking (Goldfeld \& Klar 2013), soil 83 slopes etc. 
84 In this paper the BOTDR distributed monitoring technology is briefly discussed and its application in a number of pile load test cases (both top-loaded using an external reference frame and bi-directionally loaded using an Osterberg-cell) in London is explored. The monitoring data from the distributed BOTDR and discrete VWSG technologies in the three case studies is analysed and compared to shed light on the relative merits of each approach (continuous and discrete) and highlight their necessity in future reliable pile load testing. Finally, numerical analyses were conducted for each of the three piles and the results are presented in this paper to enable a better understanding of pile behaviour under loading.

\section{Distributed fibre optic monitoring}

This section provides a brief description of the principles of BOTDR. However, the complete description of the method and the associated experimental approaches required for calibration are well beyond the scope of this paper and they are therefore not included, as they can be found elsewhere in great detail (Mohamad 2007; Iten 2011; Soga 2014; Soga et al. 2015). More information about the fundamentals of light propagation can be obtained from relevant literature in the area of photonics (Horiguchi et al. 1995) as this is out of scope of this paper. A detailed description of the theory of distributed FO strain sensing and its applications in civil and geotechnical infrastructure is given by Kechavarzi et al. (2016)

\subsection{Principle of Brillouin Optical Time Domain Reflectometry}

A fibre optic (FO) cable allows light waves from a FO analyser to travel along its entire length through total internal reflection, irrespective of the orientation of the cable itself. This allows a signal to be carried over very long distances, such as for broadband Internet. Backscattered signals are generated as the light wave passes through the optical fibre and presents itself as Rayleigh, Raman and Brillouin spectrum. Within the Brillouin backscatter, it is found that the peak frequency experiences a shift that is generally considered to be linearly proportional to applied strain. Using the measured time required for the backscattered signal to return to the analyser, the specific location at which this frequency shift is observed can 
110 be estimated accurately. Therefore, the entire fibre optic cable is essentially serving as a

111 distributed strain sensor.

112 The FO analyser sends a light with of $1550 \mathrm{~nm}$ wavelength into an optical fibre and the 113 generated Brillouin spectrum of the back-scattered light has 25-27 $\mathrm{MHz}$ bandwidth and

114 around $11 \mathrm{GHz}$ central peak frequency when no strain is applied on the fibre. The back115 scattered Brillouin central frequency, $\mathrm{v}_{\mathrm{b}}$, is related to the input light according to Eq. 1 and 116 this is provided directly from the FO analyser.

$$
v_{b}=\frac{2 \cdot n_{f} \cdot v_{a}}{\lambda_{l}}
$$

\section{Eq. 1}

119 where $\mathrm{n}_{\mathrm{f}}$ is the fibre core refractive index, $\mathrm{v}_{\alpha}$ is the acoustic velocity in the fibre and $\lambda_{l}$ is the 120 wave length of the input light.

121 Changes in temperature and/or strain induce a density change in the cable and therefore change in the acoustic velocity, $v_{\alpha}$, of the light too. As the strain or temperature at a given location change, the frequency of the backscattered light is shifted by an amount which is approximately linearly proportional to the applied strain, $\Delta \varepsilon$, or temperature, $\Delta \mathrm{T}$, according to Eq. 2.

$$
\Delta v_{b}=\Delta v_{b 0}+M \cdot \Delta \varepsilon+N \cdot \Delta T
$$

\section{Eq. 2}

128 Where, $v_{b 0}$ is the central Brillouin peak frequency at zero strain and at a given temperature, $129 \Delta \varepsilon$ is the applied strain, $\Delta \mathrm{T}$ is the temperature change, and $\mathrm{M}, \mathrm{N}$ are the coefficients for 130 strain and temperature change respectively. For an incident wavelength of $1550 \mathrm{~nm}$, the 131 Brillouin frequency shift can vary from $9 \mathrm{GHz}$ to $13 \mathrm{GHz}$ depending on the different fibre properties. Therefore knowledge about of this frequency difference can provide information about the applied strain and temperature changes at the location where the back-scattered

134 light was generated. As the speed of light is constant, the location can be evaluated by 
measuring the time since the light was initially sent into the fibre. Back-scattered light is

136 generated at every point along the entire length of the fibre and therefore by resolving both

137 time and frequency a continuous strain profile along the fibre can be determined.

138 For the case studies presented in this paper, either the AQ8603 analyser manufactured by

139 Yokogawa Electric Corporation, Japan, or the NeubreScope NBX-5000 analyser

140 manufactured by Neubrex, Japan, are employed. These are able to provide a minimum

141 readout resolution between $0.05 \mathrm{~m}$ and $0.1 \mathrm{~m}$ with a spatial resolution of 0.5 to $1.0 \mathrm{~m}$. Spatial

142 resolution implies that it produces a weighted average strain reading over 0.5 or $1 \mathrm{~m}$ at every

$1430.05 \mathrm{~m}$ length of the cable (this is considered as "spatially-continuous" or "distributed" data).

144 These settings can be changed depending on the time allocated for the specific test.

145 Essentially the technology offers a large number of strain data (every $0.05 \mathrm{~m}$ to $0.1 \mathrm{~m}$ in this 146 case) along a structure embedded with fibre optic cables.

147 In addition to the clear advantage of measuring a full strain profile, its simplicity lies in the

148 fact that only a single cable is required for the entire system, enabling its use in small 149 diameter piles and eliminating the time and effort for cable management, that would be 150 required for conventional strain gauges. No electricity is required other than to power the 151 analyser itself, which could be located much further away in a safe, and convenient location on the construction site, as light waves travel efficiently through the fibre optic cables. The result is an instrumentation system which can provide a full strain profile of the pile.

\subsection{Fibre Optic Cables}

155 Strain on an optical fibre can be generated from two sources, mechanical or thermal.

156 Therefore, two types of optical fibre cables are installed and are shown in Figure 2: Fujikura 157 4-core single mode fibres reinforced ribbon cable for strain sensing (strain sensing cable) 158 and Excel 4-core single mode fibres loose tube for temperature compensation (temperature cable). While they are both attached to the reinforcement cage, the fibre optic cores of the temperature cable sit in a gel which isolates any transfer of mechanical strains from the 
outer coating. Thus it is only subjected to thermal changes. These measurements are used

162 to compensate the readings measured from the strain cables to provide an accurate reading

163 of interest, the actual mechanical strain.

\subsection{Installation of FO Instrumentation}

Installation of FO cables is usually done on site, as described in Figure 3. Long pile foundations typically consist of a number of steel reinforcement cage segments and therefore the bottom steel cage is instrumented on the ground. The FO cables (shown in blue colour in Figure 3) are running along the entire length of the bottom segment on two opposite sides of the pile and a loop of some FO cable is made close to the bottom of the segment. The longitudinal cables are pre-strained (i.e. a tensile strain is applied) using cable clamps at the two ends of the steel cage. Once the borehole is dug, the bottom cage is inserted and while the other cages are spliced onto the bottom cage and the whole pile lowered down in the borehole, the remaining FO cable is attached to them. Finally, the two ends of the FO cable run from the top of the pile to the FO analyser.

With the pile loaded axially, it is assumed that the concrete pile will have negligible hoop strain across its cross section and therefore a $10 \mathrm{~m}$ loop cable for both strain and temperature is prepared and secured at the end of the bottom reinforcement cage to serve as a zero-strain loop for referencing and compensation purposes.

179 For the ease of data interpretation, a pre-strain of about $1000-2000 \mu \varepsilon$ is often introduced to the strain cable. Anchorage is provided on the bottom loop end by cable wire clamps before stretching the strain cable to the predetermined pre-strain. Strain cable is then secured with another set of cable wire clamps at the top of the reinforcement cage before supplementing

183 the anchorage by either spot gluing with epoxy glue or using cable ties at approximately every $0.5-1.0 \mathrm{~m}$ interval. Temperature cables are loosely secured next to the strain cables with cable ties as they are routed to the top of the cage. Figure $4(a)$ and (b) show the installed FO cables and sister-bar VWSGs on a foundation pile. 
187 Once the bottom cage has been instrumented, it is lowered into the borehole. The fibre optic

188 cables are then unwound from the reels on each side of the borehole as the cage is lowered.

189 Pre-straining is carried out for the strain cables for subsequent reinforcement cages as well

190 without epoxy glue due to time constraints. Concrete is subsequently poured in the borehole 191 and as the concrete cures the FO cables become securely embedded within the pile. Further 192 details of FO cable installation in piles established at University of Cambridge can be found 193 in (Klar et al. 2006; Soga 2014; Soga et al. 2015).

\subsection{FO data analysis}

195 As described earlier, applied strain causes a shift in the peak Brillouin frequency in the 196 optical fibre. Therefore, by measuring the frequency difference, one can obtain the applied 197 strain on the cable. Moreover, because FO cables are able to detect strains due to both 198 mechanical and thermal loads, the two components need to be analysed separately. The 199 measured frequency difference from the "temperature cable", $\Delta \mathrm{v}_{\mathrm{bT}}$, is influenced only by changes in temperature, whereas that from the "strain cable", $\Delta \mathrm{v}_{\mathrm{bs}}$, is influenced by changes 201 in both mechanical load and temperature.

202 Therefore, changes in temperature, $\Delta T$, can be obtained from Eq. 3 (where, $\mathrm{C}_{\mathrm{TT}}$ is a 203 property of the cable, obtained by calibrating the "temperature cable", which determines how temperature affects the Brillouin frequency reading of the cable and it is usually around $\left.1.1 \cdot 10^{-3} \mathrm{GHz} /{ }^{\circ} \mathrm{C}\right)$.

$$
\Delta T=\frac{\Delta v_{b T}}{C_{T T}}
$$

207 Eq. 3

208 The thermal strain, $\varepsilon_{\text {temp, }}$, (the strain that corresponds to free thermal expansion strain due to 209 temperature change) is then given by Eq. 4 (where, $\alpha_{c}$ is the thermal expansion coefficient 210 of concrete and it is usually around $9.65 \mu \varepsilon /{ }^{\circ} \mathrm{C}$ ).

$$
\varepsilon_{\text {temp }}=a_{c} \cdot \Delta T
$$


213 The real (observed) strain, $\varepsilon_{\text {real, }}$ (the actual strain that the pile experiences in the field) is then

214 given by Eq. 5 (where, $\mathrm{C}_{\mathrm{E}}$ is a property of the fibre, obtained by calibrating the "strain cable",

215 which determines how strain affects the Brillouin frequency and it is usually around $5 \cdot 10^{-4}$

$216 \mathrm{GHz} / \mu \varepsilon$; and $\mathrm{C}_{\mathrm{T}}$ is a property of the fibre that determines how the Brillouin frequency is

217 affected by temperature difference, and it is usually around $1.0 \cdot 10^{-3} \mathrm{GHz} /{ }^{\circ} \mathrm{C}$ ).

$$
\varepsilon_{\text {real }}=\frac{1}{C_{E}}\left(\Delta v_{b S}-C_{T} \cdot \Delta T\right)
$$

219 Eq. 5

220 The mechanical (constrained) strain, $\varepsilon_{\text {mech }}$, (the reaction strain that is the result of both the applied mechanical load and temperature) is then given by Eq. 6

222

$$
\varepsilon_{\text {mech }}=\varepsilon_{\text {real }}-\varepsilon_{\text {temp }}=\frac{1}{C_{E}}\left[\Delta v_{b S}-C_{T} \cdot\left(\frac{\Delta v_{b T}}{C_{T T}}\right)\right]-a_{c} \cdot \frac{\Delta v_{b T}}{C_{T T}}
$$

223 Eq. 6

224 Finally, once the strain profiles are obtained, the actual geotechnical response of the pile may be captured using Eq. 7 and Eq. 8 to determine axial force, $F_{a}(y)$, and vertical displacement, $\mathrm{u}(\mathrm{y})$, profiles respectively.

$$
F_{a}(y)=E A \cdot \varepsilon_{m e c h}(y)
$$

Eq. 7

$$
u(y)=u\left(y=y_{0}\right)+\int_{0}^{y} \varepsilon_{\text {real }}(y) d y
$$

Eq. 8

Where, EA is the axial rigidity of the pile ( $E$ is Young's modulus and $A$ is cross-sectional area) and $y$ is the depth from the top of the pile. For the vertical displacements, the relative displacements obtained from the integration of axial strains is added to available absolute displacement values from displacement transducers at $y_{0}$. The data profiles obtained from BOTDR have usually a wavy nature and therefore they need to be filtered prior to data 
analysis. The data presented in this study have been filtered using a second order Savitzky-

237 Golay (1964) filter with a 31-point frame.

\section{Case study 1: Pile load test at Broadgate Road, London.}

\subsection{Description of pile test}

240 The Broadgate Road project in London was designed to house a fourteen-storey office 241 building with two basement levels. Due to tight space restrictions along one side of the

242 project, a number of mini piles of 0.305 m diameter were constructed in close proximity to 243 support the superstructure. A high-strength steel reinforcing case was inserted in the ground 244 after the drilling process. The pile tested is $0.305 \mathrm{~m}$ diameter $(0.343 \mathrm{~m}$ at the top $6 \mathrm{~m}$ because 245 of a steel casing around the pile) and $25 \mathrm{~m}$ long, as shown in Figure 5 (a). On the same 246 figure, the soil stratigraphy is also included with some known material properties obtained 247 from relevant triaxial and simple shear laboratory tests. The pile test was carried out once 248 the concrete material achieved a specified value of minimum strength. The pile test consists 249 of three consecutive cycles of applied load (at the top of the pile) of up to $720 \mathrm{kN}, 1080 \mathrm{kN}$ and $1985 \mathrm{kN}$ for each of the three cycles, achieved after several loading and unloading steps (Figure 5 (b)). The pile was instrumented with distributed FO cables on two opposite sides of the pile and a number of discrete VWSGs along the pile depth.

\subsection{Data Interpretation}

Figure 6(a) shows the axial strain in the pile for the three peak values of the three cycles as it was captured by the FO cables and the VWSGs, whereas Figure 6(b) shows the corresponding axial force profiles (calculated from strains multiplied by the pile axial rigidity, $\mathrm{EA}$, as described by Eq. 7 and using $\mathrm{E}=30000 \mathrm{MPa}$. This value adopted for $\mathrm{E}$ was obtained following the Fellenius (1989) approach and by using the FO strain values, $\varepsilon$, at the top $30 \mathrm{~cm}$ of the pile (surrounded by soil but with insignificant influence, see Figure $6 \mathrm{a}$, Figure 9a, Figure 12a) and the applied loads, $\mathrm{P},(\mathrm{E}=\Delta \mathrm{P} / \Delta \varepsilon / \mathrm{A})$. The Fellenius method proposes a smooth linear (best-fit) reduction of secant modulus with axial strains. Therefore, a 
representative average value of $E$ over the dominant experienced strains $(\sim 300-700 \mu \varepsilon)$ was

263 adopted based on that best-fit line. It is shown that there is a generally good agreement between the two monitoring technologies. No VWSG data were obtained for the largest cycle (i.e. for loading of $1985 \mathrm{kN}$ ), as there was a malfunction of the VWSG instruments, and therefore only FO data is available for this load case. It is also shown that there is some scatter in the FO data values which is currently a known issue with distributed FO strain sensing systems. This is because the standard resolution of FO is constant and about 30$50 \mu \varepsilon$ and therefore this becomes relatively less significant for larger applied loads (which imply larger induced strains). The waviness of FO strains may offer a challenge when differentiating strain data profiles to obtain shaft friction values, but their spatial continuity allows for a distributed sensing of localised strains, e.g. necking, fracture etc., whereas, such localised features would not be identified by discrete monitoring systems (such as VWSGs).

274 Figure 6(c) shows the vertical displacements, $u$, of the pile from the FO cables. The values 275 from the FOs were obtained by integrating the strain profiles and adding those to absolute 276 displacement measurements from displacement transducers at the top of the pile, as 277 described by Eq. 8 .

278 The results of a simplified numerical finite element (FE) beam-spring model are included for 279 comparison in Figure 6. The simplified FE analysis considered a single vertical pile loaded 280 axially from the top modelled with linear beam elements and represented the surrounding soil with non-linear springs which is a practical approach as opposed to the more common way of modelling the soil with solid elements. All the beam elements and non-linear springs contribute to the global stiffness matrix and therefore the global FE equilibrium equations. Due to the nonlinear nature of the soil-spring the external load is applied incrementally and the equations are solved using an iterative Modified Newton-Raphson technique. A number of different soil layers, associated with constant soil spring properties along the depth of each layer, were considered based on the ground conditions, although they did not follow exactly the soil stratigraphy. This simplified FE analysis approach is explained in the 
289 Appendix in more detail. The behaviour of the pile was back-analysed to derive the 290 properties of the soil springs which are subsequently used in the FE analysis to calculate the 291 axial strain and vertical displacement profiles. Namely, the optimum set of properties of the 292 soil springs was obtained that was able to reproduce well the observed axial strain and 293 vertical displacement profiles from the FO readings. The values of the model parameters was obtained through a simple optimisation algorithm (here the Levenberg-Marquardt scheme was used (Levenberg 1944; Marduardt 1963)), in which the changing variables were the set of the model parameters (i.e. in this case 20 parameters, 4 for each of the 4 layers and 1 for the pile base) and the objective function was the difference of the axial strains obtained from the numerical model and those observed from the FOs. It is shown here that a good match is obtained between the field data (from FO \& VWSGs) and the FE backcalculations.

Figure 7 (a) shows the calculated shaft friction (SF) profiles for the three peak values of the three cycles, from the FE analysis. Since the FO data exhibit some (inherent) undulations, deriving SF values from the slope of the axial force might be cumbersome. Therefore, here a "synthetic" approach is followed, where a numerical model is established that reproduces accurately the monitored axial strain and vertical displacements from FOs (see Figure 6) and then SF profiles are obtained from the FE analysis of the model. This numerical analysis approach was followed here due to the inability to obtain SF values directly from the wavy FO strains. In fact, direct estimation of SF requires differentiation of axial strains which in the case of wavy strain profiles leads to unrealistically large fluctuations of SF values with the depth of the pile. It is shown here that generally larger SF values are obtained within the

311 London Clay stratum (i.e. at $z<-4 m$ ) as compared to the SF observed at the top soil layers

312 (i.e. at $z>-4 m$ ). However, it is shown that at the bottom of the pile, very small SF values are

313 mobilised, perhaps due to the small strains experienced by the pile. Since a numerical 314 optimisation procedure was followed to obtain the SF, the small values of strains 315 experienced at the bottom of the pile compared to the usual variation of FO strain data leads 
316 to a large noise-to-signal-ratio and therefore the evaluation of SF (i.e. determination of the

317 actual slope of the strain profiles) values may become cumbersome.

318 Furthermore, Figure 7 (b)(c) show the evolution of SF with the applied load, P, and the 'local'

319 vertical displacement, $\mathrm{u}$, at various depths (according to the local soil stratigraphy) along the 320 pile and the pile base pressure, $q_{b}$. Figure 7 shows that SF is mobilised early in the test, 321 whereas the pile base pressure is mobilised at later stages for higher loads. As expected the 322 SF development curves show an initial stiffness that drops with the displacement, due to the 323 plasticity of the soil close to the pile shaft. It is clearly observed that the first layer $(0-6 \mathrm{~m})$, which is covered by the pile casing does not show significant development of strains and approximately reaches an ultimate value of SF of about $20 \mathrm{kPa}$. Besides, although the three layers considered within the London Clay show variable SF development, it is accepted that the majority of the London Clay reaches SF of about $70-100 \mathrm{kPa}$, whereas the bottom of the London Clay shows minimal development of SF. However, this could probably be due to the small layer thickness considered in the data analysis (FO data exist in layer 4 between $y=19$ 22.5m). Nevertheless, in general, the evolution of shaft friction with the vertical displacements seems to reach (roughly) a plateau for displacements of about $0.01-0.03 \mathrm{~m}$ which is slightly less than $10 \%$ of the pile diameter.

333 Finally, Figure 7 (d) shows the relevant design t-z and q-z curves following the API (2002) methodology (see Appendix B). Although there are some differences between the observed (Figure 7 (c)) and design (Figure 7 (d)) curves, in general they seem to agree quite well yielding comparable values of ultimate pile shaft and base resistance.

\subsection{Remarks}

338 A typical interpretation of the geotechnical data would consider Eq. 9 and Eq. 10 to calculate the ultimate shaft capacity, $\mathrm{q}_{\mathrm{s}}$, and Eq. 11 and Eq. 12 for the base capacity, $\mathrm{q}_{\mathrm{b}}$ of the pile (Salgado 2008; Knappett \& Craig 2012; Tomlinson \& Woodward 2014).

$$
q_{s(\text { cohesive })}=\alpha \cdot S_{u}
$$


Eq. 9

$$
q_{s(\text { non-cohesive })}=\beta \cdot \sigma_{v o}^{\prime}=K_{o} \cdot \tan \delta \cdot \sigma_{v o}^{\prime}
$$

344 Eq. 10

345

$$
q_{b(\text { cohesive })}=N_{c} \cdot S_{u}
$$

Eq. 11

$$
q_{b(\text { non-cohesive })}=N_{q} \cdot \sigma_{v o}^{\prime}
$$

348

Eq. 12

where, a (usually around 0.5 for London Clay (Tomlinson 1997)) is the empirical shaft coefficient, $K_{\circ}$ is the earth pressure at rest, $\delta$ (usually around $0.75 \varphi$ ) (Stas \& Kulhawy 1984) is the pile-soil interface friction angle and $\mathrm{N}_{\mathrm{q}}$ (usually around 50 (Berezantzev, Khristoforov \& Golubkov 1961; Knappett \& Craig 2012)) and $\mathrm{N}_{\mathrm{c}}$ (usually its value is taken as 9 (Kulhawy \& Prakoso 1999)) are the base bearing capacity coefficients.

Using the above equations and the geotechnical data in Figure 5 one would obtain an ultimate value of shaft capacity of $8 \mathrm{kPa}$ for the first layer (using Eq. 10) and about 32$120 \mathrm{kPa}$ for the second layer (using Eq. 9). These values compare well with the calculated values from FO in Figure 7, which suggest around 20kPa for the first layer and about 10$120 \mathrm{kPa}$ for the second layer. If one was to back calculate the values of $\alpha$ and $\beta$, then, the first layer would yield a value of $\beta=0.5$ (whereas Eq. 10 yields $\beta=0.2$ ) and layers $2-4$ would yield values of $\alpha=0.9,0.89,0.1$ respectively (whereas the common assumption is 0.5 (Tomlinson 1997)).

Similarly, when calculating the ultimate base capacity, one would obtain about 2MPa when using Eq. 11 (i.e. based on $\mathrm{S}_{u}$ ) and about 25MPa when using Eq. 12 (i.e. based on $\mathrm{c}$ and $\varphi)$. These values are different and below and well above the (linear) 6MPa that was observed from the FOs during this test respectively. This is unexpected and it could be due to a number of possible reasons, e.g. it may suggest that the relation usually used for the pile base bearing capacity (Eq. 11) might be significantly unconservative or it may suggest 
that the material parameter values used to calculate $\sigma_{v o}^{\prime}$ were too small. Nevertheless, it is observed here that Eq. 11 (i.e. $\mathrm{S}_{\mathrm{u}}$ ) provides a better estimate.

370

The ability to fit a numerical model to the monitoring data (in particular, the continuous vertical displacement profile) to further understand the behaviour of piles is a great advantage. More confidence in the results of the back-analysed model is built when a continuous strain profile is available which can show the full picture of the strains over the whole length of the pile and by direct integration it may give reliable estimates of pile displacements. Finally, the benefits of obtaining such a relevant numerical model can include the development of load transfer curves derived from the calculated shaft friction with respect to the vertical displacement.

\section{Case study 2: Pile load test at East Village, London.}

\subsection{Description of pile test}

The second case study considers a pile test at East Village (former Athletes Village) in Stratford, London. The examined pile is $32 \mathrm{~m}$ long with $900 \mathrm{~mm}$ diameter $(930 \mathrm{~mm}$ at the top $14 \mathrm{~m})$. The local soil stratigraphy consists of Made Ground, Alluvium and River Terrace Deposit finishing at around $14 \mathrm{~m}$ depth and along which the pile is covered by a $15 \mathrm{~mm}$-thick steel casing. These layers are followed by two thick layers of Lambeth Group and Thanet Sand that interface at a depth of $23 \mathrm{~m}$. Information about pile geometry, soil stratigraphy and some basic soil properties are given in Figure 8(a). The pile test consists of a static maintained load applied at the top of the pile following two cycles of loading-unloading until the pile fails. Details about the pile test sequence are shown in Figure $8(b)$. Similar to the previous case, the pile was instrumented with distributed FO cables and discrete VWSGs; the latter were installed at various locations along the pile depth.

\subsection{Data Interpretation}

Figure $9(a)(b)$ show the monitored axial strains and the calculated axial force in the pile for three selected load stages from both the FOs and the VWSGs. Similar to the previous case, 
although the FOs show some scatter in the data, a good agreement is obtained between the two sensors for both strains and forces. Observed strains and forces are roughly constant for the first $14 \mathrm{~m}$ which suggests that minor shaft friction is developed over that depth. This was expected as the pile is surrounded by a steel casing at the top $14 \mathrm{~m}$. Moreover, at depths below $14 \mathrm{~m}$, the axial strains and forces drop, which is due to the interaction with the surrounding soil and the developed soil-pile interface friction. Additionally, on the same graphs, the results of a simple FE analysis (similar to the one used in the first case, see Appendix A for more details and model parameters) are included (the strain step in the first

402 figure is due to the change of pile diameter and hence the axial stiffness EA). This analysis was conducted to match the observed axial strains and vertical displacements in Figure 9 (a) and (c). The latter figure shows that the vertical displacements obtained by the direct integration of the observed axial strains match the displacements resulting from the FE model that reproduces the axial strains.

407 Figure 10 (a) shows the calculated shaft friction, SF, profiles for the three selected load cases as these were determined from the FE analysis. Again, these were obtained from the FE model that was calibrated to reproduce accurately the monitored axial strain and vertical 410 displacements from FOs (see Figure 9). Furthermore, Figure 10(b)(c) show the evolution of 411 SF with the applied load, P, and the 'local' vertical displacement, $\mathrm{u}$, at three selected depths 412 along the pile, according to the local soil stratigraphy, i.e. in the shallow layers (covered with 413 pile casing), Lambeth Group and Thanet Sand. It is firstly observed that the first layer, which 414 is covered by the pile casing does not show significant development of strains and approximately reaches an ultimate value of SF of about $40 \mathrm{kPa}$. In contrast, Lambeth Group

416 and Thanet Sand do exhibit a larger development of SF that reaches around $200 \mathrm{kPa}$ and $417110 \mathrm{kPa}$ respectively. This difference was expected as the pile in the latter two layers was not 418 covered with a steel casing and therefore pile-soil interaction friction develops resisting the 419 pile movement. In general, as expected, the SF development curves show an initial stiffness that drops with the displacement, due to the plastic deformation of the soil close to the pile 
421 shaft. Finally, it is again shown that SF is mobilised early in the test, whereas the pile base 422 pressure in mobilised at later stages for higher loads.

423 Finally, Figure 10 (d) shows the relevant design t-z and q-z curves following the API (2002) methodology. Although there are some differences between the observed (Figure 10 (c)) and design (Figure 10 (d)) curves, in general they seem to agree quite well yielding comparable values of ultimate pile shaft resistance.

\subsection{Remarks}

Using Eq. 9 - Eq. 12 and the geotechnical data in Figure 8 one would obtain an ultimate 430 value of shaft capacity of $29 \mathrm{kPa}$ for the first layer (using Eq. 10), 32-219kPa for the second layer (using Eq. 9) and about 116kPa for the third layer (using Eq. 10). These values compare very well with the observed values from FO in Figure 10, which suggest around $30 \mathrm{kPa}, 200 \mathrm{kPa}$ and $110 \mathrm{kPa}$ for the three layers.

434 If one was to back calculate the values of $\alpha$ and $\beta$, then, the first layer would yield a value of 435 $\beta=0.21$ (whereas Eq. 10 yields around $\beta=0.2$ ), layer 2 would yield a values of $\alpha=0.8$ (whereas the common assumption is 0.5 (Tomlinson 1997)) and the third layer a value of $\beta=0.2$ (in agreement to Eq. 10 that yields around $\beta=0.2$ too). So, in the case, the $\beta$-method seems to work well, whereas the appropriate value for $\alpha$ is slightly larger than the commonly used (0.5).

440 Similarly, when calculating the ultimate base capacity, one would obtain about 27MPa using 441 Eq. 12 (i.e. based on $\mathrm{c}$ and $\varphi$ ) which is well above the (roughly linear) $12 \mathrm{MPa}$ that was 442 observed from the FOs during this test. Again, the relation for the base capacity seems to 443 overestimate significantly the observed pile base capacity. 


\subsection{Description of pile test}

446 This particular case study focuses on the behaviour of a $31.5 \mathrm{~m}$-long, $1500 \mathrm{~mm}$ diameter 447 bored pile during a preliminary load test at the Francis Crick Institute. This is a biomedical 448 research centre situated next to St. Pancras International train station in the London 449 Borough of Camden. One of the key differences from the previous case studies is the loading mechanism. Bi-directional Osterberg Cells (O-Cell) (Osterberg 1984) were used to apply load from the bottom of the pile. Figure 11(a) shows the geometry of the pile and the

452 local stratigraphy; the ground consists of two thick layers of London Clay and Lambeth 453 Group, with varying undrained strength, overlying Thanet Sand.

Similar to the previous case study, Fujikura reinforced ribbon cable (JBT-03813) and 8 core single mode fibre (205-301 Excel OS1 8C 9/125 Loose Tube LSOH Black) were used for measuring strain and temperature respectively. The installation process was identical to case study 1 where both fibre optic cables were routed along opposite sides of the reinforcement cage from the pile head to the top of O-Cell where a $10 \mathrm{~m}$ long reference loop was located. A pre-strain of $2000 \mu \varepsilon$ was induced in the strain cable during installation. Anchorage was provided by IC-ROC clamps manufactured by Fujikura. To serve as a comparison, 5 levels of VWSG were installed at 5 levels along the pile depth. The pile test consisted of a single load cycle reaching a maximum of $8.33 \mathrm{MN}$ after 7 loading steps and then unloading to zero after 3 steps, as shown in Figure 11 (b).

\subsection{Data Interpretation}

Figure 12(a) shows the measured axial strain profiles of the pile for three selected load stages from FO and VWSGs. Considering firstly the VWSGs only, it is shown that, as expected, large values of strain occur at the bottom of the pile (close to the O-cell) and smaller values occur at the top. Interestingly, at a depth of about $19 \mathrm{~m}$, there is a significantly higher value of WWSG strain which, in practice, could be considered as not representative of

470 the actual strains in the pile and therefore ignored and discarded by the design engineers. 
471 Eliminating outliers that do not conform to the expected ranges is common in data

472 interpretation as instrument malfunctions do occur occasionally. Signs of VWSG malfunction

473 may not always be clear and these anomalies can be caused by a number of scenarios such

474 as cable damage. In some cases the recorded data is in fact a true representation which can

475 be attributed to changes in ground conditions and construction quality.

476 However, it is observed that the fibre optic cable picks some unexpectedly high values of 477 strain at a depth of about $18-23 \mathrm{~m}$. This is unexpected when the pile diameter is uniform at 478 that depth and therefore no step is expected in the axial strains. The data indicates that the 479 pile sustained high localised strains in that region. Similarities in trend for both systems 480 triggered a further investigation into the soil strata where the nearest borehole log $(\mathrm{BH} 04)$ 481 (distance $\sim 10 \mathrm{~m}$ ) recorded a change in soil layers from lignite beds and lower mottled beds in 482 the Lambeth group at around $18-19$ m depth. Although such a scenario was not reported in 483 the construction records, the presence of sandy glauconitic clay may have caused a 484 localised collapse during the construction of the pile which may have caused necking of the 485 pile (smaller cross-section). Subsequently, the cross sectional area, A, as well as the 486 integrity of the concrete (e.g. Young's modulus, E) at this location would have been compromised. Therefore, a much higher strain reading would be very likely $\left(\varepsilon_{a}=F_{a} / E A\right)$.

488 Computing the axial force by multiplying the axial strains with a constant axial stiffness, EA, 489 would therefore be unrealistic. Here, a FE model was employed again in which the axial 490 rigidity, EA, of the pile was kept constant along the pile depth, except at depth of $18-23 \mathrm{~m}$ at 491 which it was reduced. After a parametric study, it was found that, when EA at that location 492 was reduced down to $35 \%$ of the initial EA (using again $E=30000 \mathrm{MPa}$ and $A=0.25 \pi \mathrm{d}^{2}$, 493 where $d$ is the design diameter shown in Figure 11), a good match was obtained between 494 the axial strains (Figure 12 (a)) and the vertical displacements (Figure 12 (c)). This apparent 495 reduction in EA could be due to some pile necking (smaller A) or some mixing of the pile 496 concrete with adjacent ground materials (smaller E). Then, using the results of the FE 497 model, the axial force profiles in the pile were calculated by multiplying the axial strains by 
EA everywhere except at depth $18-23 \mathrm{~m}$ where $0.35 \mathrm{EA}$ was used. The latter profiles are

499 shown in Figure 11 (b) along with the axial force from the FE model. It is shown that a good 500 comparison was obtained between the two monitoring instruments and the relevant 501 numerical analysis. As it may be observed the axial force profiles with the non-uniform EA 502 vary smoothly with the depth (in contrast to the axial strain profiles) and this is expected because of force equilibrium (since the soil spring stiffness values have not been changed).

504 It is appreciated here that the use of 0.35EA for the pile analysis is not ideal and it was 505 literally obtained from a back-analysis matching the observed strain profiles. Perhaps 506 another option would be to conduct a series of solid FE analyses (e.g. 2D axisymmetric) 507 which consider different values of reduced $E$ (of blended concrete and soil) and reduced $A$ 508 (i.e. reduced $d^{2}$ ).

509 Figure 13 (a) shows the calculated shaft friction, SF, profiles for the three chosen values of 510 applied load, from the FE analysis. Again, these were obtained from the FE model that 511 reproduced accurately the monitored axial strain and vertical displacements from FOs (see 512 Figure 12). Furthermore, Figure 13(b)(c) show the evolution of SF with the applied load, P, 513 and the 'local' vertical displacement, $u$, at two selected depths along the pile, according to 514 the local soil stratigraphy, i.e. in the London Clay and the Lambeth Group. It is shown that

515 Lambeth Group which is deeper and closer to the O-cell exhibits early development of shaft 516 friction with the applied load, $\mathrm{P}$, and that it has a stiffer response than the upper London 517 Clay, which seems to reach a SF plateau of about $35 \mathrm{kPa}$ at about $0.01 \mathrm{~m}$ displacement. In 518 contrast, Lambeth Group shows an increasing development of SF which has not reached an 519 ultimate value in this test.

520 Finally, Figure 13 (d) shows the relevant design t-z curves following the API (2002) 521 methodology. Once again, although there are some differences between the observed 522 (Figure 13 (c)) and design (Figure 13 (d)) curves, in general they seem to agree quite well 523 providing similar values of ultimate pile shaft resistance. 
525 The monitoring data from the FO cables agree very well with the monitoring data from the WWSG. Moreover, the continuity of the FO data is able to highlight a region of localised high strain development which spreads over $6-8 \mathrm{~m}$ in the pile shaft. A high value of strain was also captured by the WWSG sensors at the same depth, but as this was only a single value it could easily have been ignored and its significant difference from the other data points be erroneously attributed to instrument malfunction. However, the presence of continuous FO data here was able to support the localised high values of strain which might be due to some low quality concrete material of the pile or some mixing of ground material with pile concrete.

533 Moreover, the availability of these monitoring data allows the derivation of shaft friction development curves with the applied load or vertical displacement. These curves show that the developed shaft friction in the deeper soil layers (e.g. Lambeth Group), i.e. closer to the O-cell is, as expected, higher than the corresponding friction at the top of the pile, close to the ground surface.

Using Eq. 9 (i.e. based on $S_{u}$ ) and the geotechnical data in Figure 11 one would obtain an ultimate value of shaft capacity of $23-98 \mathrm{kPa}$ for the first layer and about $100-121 \mathrm{kPa}$ for the second layer. These values compare well with the observed values from FO in Figure 13, which suggest average values of around $30 \mathrm{kPa}$ and $150 \mathrm{kPa}$ for the two layers. It is shown

542 that the shaft friction values interpreted from the observed FO data are very close to the

543 expected design based on Eq. 9. Finally, if one was to back calculate the values of $\alpha$ in Eq.

5449 , then, the two layers would yield values of $\alpha=0.25$ and $\alpha=0.68$ respectively (whereas the 545 common assumption is 0.5 (Tomlinson 1997)).

\section{Conclusions}

547 This paper presents the application of distributed fibre optic strain measurement technology 548 for monitoring the actual field behaviour of axially loaded piles. The fibre optic data from 549 three representative case studies of pile load tests conducted recently in London are 
analysed and compared to spatially-discrete point VWSGs and relevant simple finite-element analyses. The main findings of this study are the following:

552

- The BOTDR distributed monitoring system is able to provide a continuous profile of the induced strain within piles and this offers more confidence in determining the developed shaft friction profiles along the pile. It is also shown that the availability of continuous strain measurements offers a clear view of the condition of the entire pile and hence provides an indication of any localised regions of weakness, shaft area inhomogeneity or strain concentration. This is clearly a limitation of discrete monitoring systems such as VWSG, which do not provide adequate information for the whole length of the pile.

560

- The distributed FO data can provide reliable information about vertical pile displacements by direct integration of the spatially-continuous strain data. The calculated displacements from the FO strains were verified against the displacements obtained from a relevant FE model. It was found that such vertical displacement profiles are very useful in calibrating the model parameters of a FE model.

572

- An available and reliable set of monitoring data over the whole length of the pile allows an estimation of the shaft friction development curves with the applied load or vertical displacement (load-transfer) which may be used in future design of piles in a similar geographical region and soil stratigraphy.

- The obtained values of shaft friction and base resistance were compared with expected values from existing methods of geotechnical design (e.g. $\alpha$ and $\beta$ methods) and were generally found to be in good agreement. The "observed" values 
of $\alpha$ and $\beta$ were back-analysed and were also found to be, in general, in good agreement with the suggested values from the literature.

578

579

- The obtained load-transfer (t-z and $q-z)$ curves were compared with design curves 580 from the literature $(\mathrm{API})$. Although notable differences were observed regarding the pile base curves, the pile shaft curves were generally in good agreement.

\section{Acknowledgements}

583 This research was conducted within the Centre for Smart Infrastructure and Construction 584 (CSIC) of the University of Cambridge, funded by EPSRC and Innovate UK. Their financial 585 assistance is gratefully acknowledged. Also, the assistance of the CSIC team is 586 acknowledged, including Professor Lord Robert Mair, Dr Jennifer Schooling, Peter Knott, 587 Jason Shardelow and Jules Birks. Finally, the Authors would like to acknowledge the 588 contribution of the numerous CSIC Industry partners, especially ARUP (Duncan Nicholson, 589 Paul Morrison, Stuart Pennington), Cementation Skanska (Andrew Bell, Martin Pedley, Rab 590 Fernie) and Laing O'Rourke.

\section{$591 \quad$ Nomenclature}

$592 \quad$ A - pile cross-sectional area

$593 \quad C_{E}$ - optical fibre parameter

$594 \quad \mathrm{C}_{\mathrm{T}}$ - optical fibre parameter

$595 \quad \mathrm{C}_{\mathrm{TT}}$ - optical fibre parameter

$596 \quad d-$ nonlinear model degradation parameter

$597 \quad$ D - pile diameter

$598 \quad E-$ pile Young's modulus 
$599 \quad F_{a}-$ axial pile force

$600 \mathrm{~h}-$ nonlinear model hardening parameter

$601 \mathrm{k}_{\mathrm{m}}$ - nonlinear model maximum subgrade modulus parameter

$602 \mathrm{~L}-$ total length of pile

$603 \quad M-$ optical fibre strain coefficient

$604 \quad \mathrm{~N}$ - optical fibre temperature coefficient

$605 N_{c}-$ pile end bearing capacity factor

$606 \mathrm{n}_{\mathrm{f}}-$ fibre core refractive index

$607 \quad \mathrm{P}-$ top load value

$608 q_{b}-$ pile base pressure

$609 r$ - pile radius

610 SF - shaft friction

$611 S_{u}-$ undrained soil shear strength

$612 \mathrm{t}$ - nonlinear model shear stress parameter

$613 t_{m}$ - nonlinear model maximum shear stress parameter

$614 \mathrm{u}$ - vertical displacement

$615 v_{\alpha}-$ acoustic velocity in the optical fibre

$616 v_{b}-$ central Brillouin frequency

$617 V_{b 0}-$ central Brillouin frequency at zero strain and temperature difference

$618 y-$ depth 
$\alpha-$ adhesion factor

$621 \Delta T-$ temperature change

$622 \Delta v_{b s}-$ Brillouin frequency change reading from "strain cable"

$623 \Delta \mathrm{v}_{\mathrm{b} T}-$ Brillouin frequency change reading from "temperature cable"

$624 \quad \mathrm{Y}$ - soil unit weight

$625 \varepsilon_{a}-$ axial pile strain

$626 \varepsilon_{\text {mech }}-$ mechanical strain

$627 \varepsilon_{\text {real }}-$ real (observed) strain

$628 \varepsilon_{\text {temp }}-$ thermal expansion strain

$629 \lambda_{1}$ - wavelength of the input light

$630 \quad v$ - Poisson's ratio

\section{References}

632 Abchir, Z, Burlon, S, Frank, R, Habert, J \& Legrand, S 2015, 't-z curves for piles from 633 pressuremeter test results', Géotechnique, vol 66, no. 2, pp. 137-148.

634 Acikgoz, MS, Pelecanos, L, Giardina, G, Aitken, J \& Soga, K 2017, 'Distributed sensing of a 635 masonry vault during nearby piling', Structural Control and Health Monitoring, vol 24, no. 3, 636 p. e1872.

637 Acikgoz, MS, Pelecanos, L, Giardina, G \& Soga, K 2016, 'Field monitoring of piling effects 638 on a nearby masonry vault using distributed sensing.', International Conference of Smart 639 Infrastructure and Construction, ICE Publishing, Cambridge. 
640 API 2002, 'API Recommended Practice. Planning, Designing and Constructng Fixed

641 Offshore Platforms - Working Stress Design', American Petroleum Institute, 2A-WSD,

642 American Petroleum Institute.

643 Bathe, KJ 1996, Finite Element Procedures, 1st edn, Prentice Hall, New Jersey.

644 Berezantzev, VG, Khristoforov, VS \& Golubkov, VN 1961, 'Load bearing capacity and 645 deformation of piled foundations', Proc. 5th Int. Conf. on Soil Mechanics and Foundation 646 Engineering, Paris.

647 Bustamante, M \& Gianeselli, L 1982, 'Pile bearing capacity predictions by means of static', 648 Proc., 2nd European Symp. on Penetration Testing, Amsterdam.

649 Butterfield, R \& Banergee, PK 1971, 'The elastic analysis of compressible piles and pile 650 groups', Geotechnque, vol 21, no. 1, pp. 43-60.

651 Cheung, L, Soga, K, Bennett, PJ, Kobayashi, Y, Amatya, B \& Wright, P 2010, 'Optical fibre 652 strain measurement for tunnel lining monitoring', Proceedings of the ICE - Geotechnical 653 Engineering, vol 163, no. 3, pp. 119-130.

654 Comodromos, EM \& Bareka, SV 2009, 'Response evaluation of axially loaded fixed-head 655 pile groups in clayey soils', International Journal for Numerical and Analytical Methods in 656 Geomechanics, vol 33, no. 17, pp. 1839-1865.

657 de Battista, N, Elshafie, MZEB, Soga, K, Williamson, M, Hazelden, G \& Hsu, YS 2015, 658 'Strain monitoring using embedded distributed fibre optic sensors in a sprayed concrete 659 tunnel lining during the excavation of cross-passages', 7th International Conference on 660 Structural Health Monitoring and Intelligent Infrastructure (SHMII7), Torino, Italy.

661 de Battista, N, Kechavarzi, C, Seo, H, Soga, K \& Pennington, S 2016, 'Distributed fibre optic 662 sensors for measuring strain and temperature of cast-in-situ concrete test piles', 
663 Proceedings of the International Conference on Smart Infrastructure and Construction 664 (ICSIC), Thomas Telford, Cambridge, UK.

665 Di Murro, V, Pelecanos, L, Soga, K, Kechavarzi, C, Morton, RF \& Scibile, L 2016, 666 'Distributed fibre optic long-term monitoring of concrete-lined tunnel section TT10 at CERN.', 667 International Conference of Smart Infrastructure and Construction, ICE Publishing, 668 Cambridge.

669 Doherty, P, Igoe, D, Murphy, G, Gavin, K, Preston, J, McAvoy, C, Byrne, BW, McAdam, R, 670 Burd, HJ, Houlsby, GT, Martin, CM, Zdravkovic, LT, Taborda, DMG, Potts, DM, Jardine, RJ, 671 Sideri, M, Schroeder, FC, Muir Wood, A, Kallehave, D \& Skov Gretlund, J 2015, 'Field 672 validation of fibre Bragg grating sensors for measuring strain on driven steel piles', 673 Géotechnique Letters, vol 5, no. 2, pp. 74-79.

674 Eslami, A \& Fellenius, BH 1997, 'Pile capacity by direct CPT and CPTU methods applied to 675102 case histories', Can. Geotech. J, vol 34, pp. 886-904.

676 Fellenius, BH 1989, 'Prediction of pile capacity', ASCE Symposium on Predicted and 677 Observed Behavior of Piles.

678 Frank, R \& Zhao, SR 1982, 'Estimating the Settlement of Axially Loaded Bored Piles in Fine 679 Sand by PMT Data', Bull. Liaison LPC, vol 119.

680 Goldfeld, Y \& Klar, A 2013, 'Damage Identification in Reinforced Concrete Beams Using 681 Spatially Distributed Strain Measurements', Journal of Structural Engineering, vol 139, no. 682 12, pp. 1-11.

683 Hauswirth, D, Puzrin, AM, Carrera, A, Standing, JR \& Wan, MSP 2014, 'Use of fibre-optic 684 sensors for simple assessment of ground surface displacements during tunnelling', 685 Geotechnique, vol 64, no. 10, pp. 837-842. 
686 Horiguchi, T, Shimizu, K, Kurashima, T, Tateda, M \& Koyamada, Y 1995, 'Development of a 687 distributed sensing technique using Brillouin scattering', Journal of Light-wave Technology, 688 vol 13, no. 7, pp. 1296-1302.

689 Iten, M 2011, 'Novel applications of distributed fiber-optic sensing in geotechnical 690 engineering', PhD Thesis, ETH, Zurich.

691 Jardine, RJ \& Chow, FC 1996, 'New design methods for offshore piles', MTD, Centre for 692 Petroleum and Marine Technology (CPMT), 96/103, London.

693 Kechavarzi, C, Soga, K, de Battista, N, Pelecanos, L, Elshafie, MZEB \& Mair, RJ 2016, 694 Distributed Fibre Optic Strain Sensing for Monitoring Civil Infrastructure, Thomas Telford, 695 London.

Kersey, AD \& Morey, WW 1993, 'Multiplexed Bragg grating fibre-laser strain-sensor system 697 with mode-locked interrogation', Electron. Lett, vol 29, no. 1, pp. 112-114.

698

Kitiyodom, P \& Matsumoto, T 2003, 'A simplified analysis method for piled raft foundations in 699 non-homogeneous soils.', International Journal for Numerical and Analytical Methods in 700 Geomechanics, vol 27, pp. 85-109.

701 Klar, A, Bennett, PJ, Soga, K, Mair, RJ, Tester, P, Fernie, R, St John, HD \& Thorp-Peterson, 702 G 2006, 'Distributed strain measurement for pile foundations', Proceedings of the ICE 703 Geotechnical Engineering, vol 159, no. 3, pp. 135-144.

704 Klar, A, Dromy, I \& Linker, R 2014, 'Monitoring tunneling induced ground displacements 705 using distributed fiber-optic sensing', Tunnelling and Underground Space Technology, vol $706 \quad 40$, pp. 141-150.

707 Knappett, JA \& Craig, RF 2012, Craig's Soil Mechanics, 8th edn, CRC Press, London.

708 Kraft, ML, Ray, RP \& Kakaaki, T 1981, 'Theoretical t-z curves', J. Geotech. Engrg. Div. 709 ASCE, vol 107, no. 11, pp. 1543-1561. 
710 Kulhawy, FH \& Prakoso, WA 1999, 'Discussion of "End Bearing Capacity of Drilled Shafts in

711 Rock', J. Geotech Eng ASCE, vol 125, no. 12, pp. 1106-1109.

712 Kurashima, T, Horiguchi, T, Izumita, H \& Tateda, M 1993, 'Brillouin Optical-Fiber Time

713 Domain Reflectometry', IEICE Transactions on Cummunications, vol E76-B, no. 4, pp. 382714390.

715 Lee, CY 1993, 'Pile group settlement analysis by hybrid layer approach', Journal of the 716 Geotechnical Engineering Division, ASCE, vol 119, no. 6, pp. 984-997.

717 Lee, W, Lee, W, Lee, S \& Salgado, R 2004, 'Measurement of pile load transfer using the

718 Fiber Bragg Grating sensor system', Canadian Geotechnical Journal, vol 41, no. 6, pp. 12227191232.

720 Lehane, BM, Jardine, RJ, Bond, AJ \& R., F 1993, 'Mechanisms of shaft friction in sand from 721 instrumented pile tests', Journal of Geotechnical Engineering, vol 119, no. 1, pp. 19-35.

722 Levenberg, K 1944, 'A Method for the Solution of Certain Non-Linear Problems in Least 723 Squares', Quarterly of Applied Mathematics, vol 2, pp. 164-168.

724 Linker, R \& Klar, A 2015, 'Detection of Sinkhole Formation by Strain Profile Measurements 725 Using BOTDR: Simulation Study', Journal of Engineering Mechanics, pp. 1-10.

726 Liu, J \& Zhang, M 2012, 'Measurement of residual force locked in open-ended pipe pile 727 using FBG-based sensors', Electron. J. Geotech. Eng, vol 17, pp. 2145-2154.

728 Marduardt, D 1963, 'An Algorithm for Least-Squares Estimation of Nonlinear Parameters', 729 SIAM Journal on Applied Mathematics, vol 11, no. 2, pp. 431-441.

730 McCabe, BA \& Lehane, BM 2006, 'Behavior of Axially Loaded Pile Groups Driven in Clayey 731 Silt', Journal of Geotechnical and Geoenvironmental Engineering, vol 132, no. 3, pp. 401732 410. 
733 Ménard, L 1963, 'Calcul de la force portante des fondations à partir des essais 734 pressiométriques', Sols-Soils, vol 6, pp. 9-27.

735 Meyerhof, GG 1965, 'Shallow foundations', Journal of Soil Mechanics and Foundations 736 Division, ASCE, vol 91, no. 2, pp. 21-31.

737 Mohamad, H 2007, 'Distributed optical fibre strain sensing of geotechnical structures. PhD 738 Thesis', University of Cambridge, Cambridge, UK.

739 Mohamad, H, Bennett, PJ, Soga, K, Mair, RJ \& Bowers, K 2010, 'Behaviour of an old 740 masonry tunnel due to tunnelling-induced ground settlement', Geotechnique, vol 60, no. 12, 741 pp. 927-938.

742 Mohamad, H, Soga, K, Bennett, PJ, Mair, RJ \& Lim, CS 2012, 'Monitoring Twin Tunnel 743 Interaction Using Distributed Optical Fiber Strain Measurements', Journal of Geotechnical 744 and Geoenvironmental Engineering, vol 138, no. 8, pp. 957-967.

745 Mohamad, H, Soga, K, Pellew, A \& Bennett, PJ 2011, 'Performance Monitoring of a Secant746 Piled Wall Using Distributed Fiber Optic Strain Sensing', Journal of Geotechnical and 747 Geoenvironmental Engineering, ASCE, vol 137, no. 12, pp. 1236-1243.

748 Osterberg, JO 1984, 'A new simplified method for load testing drilled shafts', Foundation 749 Drilling, ADSC.

750 Ouyang, Y, Broadbent, K, Bell, A, Pelecanos, L \& Soga, K 2015, 'The use of fibre optic 751 instrumentation to monitor the O-Cell load test on a single working pile in London', 752 Proceedings of the XVI European Conference on Soil Mechanics and Geotechnical 753 Engineering, Edinburgh.

754 Pelecanos, L \& Soga, K 2017, 'Using distributed strain data to evaluate load-transfer curves 755 for axially loaded piles', Journal of Geotechnical \& Geoenvironmental Engineering, ASCE 756 (Submitted). 
Pelecanos, L, Soga, K, Chunge, MPM, Ouyang, Y, Kwan, V, Kechavarzi, C \& Nicholson, D

758 2017, 'Distributed fibre-optic monitoring of an Osterberg-cell pile test in London.',

759 Geotechnique Letters, vol 7, no. 2, pp. 1-9.

760 Pelecanos, L, Soga, K, Hardy, S, Blair, A \& Carter, K 2016, 'Distributed fibre optic monitoring 761 of tension piles under a basement excavation at the V\&A museum in London.', International 762 Conference of Smart Infrastructure and Construction, ICE Publishing, Cambridge.

763 Poulos, HG 1989, 'Pile behaviour - theory and application', Geotechnique, vol 39, no. 3, pp. $764 \quad 365-415$.

765 Poulos, HG \& Davis, EH 1974, Elastic solutions for soil and rock mechanics, Wiley, New 766 York.

767 Randolph, MF 2003, 'Science and empiricism in pile foundation design', Geotechnique, vol 768 53 , no. 10 , pp. $847-875$.

Salgado, R 2008, The engineering of foundations, McGraw Hill, New York.

770 Savitzky, A \& Golay, MJE 1964, 'Smoothing and Differentiation of Data by Simplified Least 771 Squares Procedures', Analytical Chemistry, vol 36, no. 8, pp. 1627-1639.

772 Schwamb, T \& Soga, K 2015, 'Numerical modelling of a deep circular excavation at Abbey 773 Mills in London', Geotechnique, vol 65, no. 7, pp. 604-619.

774 Schwamb, T, Soga, K, Mair, RJ, Elshafie, MZEB, R., S, Boquet, C \& Greenwood, J 2014, 775 'Fibre optic monitoring of a deep circular excavation', Proceedings of the ICE - Geotechnical 776 Engineering, vol 167, no. 2, pp. 144-154.

777 Seo, H-J, Pelecanos, L, Kwon, Y-S \& Lee, IM 2017, 'Net load-displacement estimation in 778 soil-nail pullout tests', Proceedings of the Institution of Civil Engineers - Geotechnical 779 Engineering, pp. 1-14. 
780 Soga, K 2014, 'XII Croce Lecture: Understanding the real performance of geotechnical 781 structures using an innovative fibre optic distributed strain measurement technology', Rivista 782 Italiana di Geotechnica, vol 4, pp. 7-48.

783 Soga, K, Kechavarzi, C, Pelecanos, L, de Battista, N, Williamson, M, Gue, CY, Di Murro, V \& 784 Elshafie, M 2017, 'Distributed fibre optic strain sensing for monitoring underground 785 structures - Tunnels Case Studies ', in S Pamukcu, L Cheng (eds.), Underground Sensing, 786 1st edn, Elsevier.

787 Soga, K, Kwan, V, Pelecanos, L, Rui, Y, Schwamb, T, Seo, H \& Wilcock, M 2015, 'The role 788 of distributed sensing in understanding the engineering performance of geotechnical 789 structures', Proceedings of the XVI European Conference on Soil Mechanics and 790 Geotechnical Engineering, Edinburgh.

791 Stas, CV \& Kulhawy, FH 1984, 'Critical evaluation of design methods for foundation under 792 axial uplift \& compression loading', Electric Power Research Institute, EL-3771, Palo Alto.

793 Tomlinson, MJ 1997, 'The adhesion of piles driven in clay', Proc. 4th Intern. Conf. Soil. 794 Mech., London.

795 Tomlinson, M \& Woodward, J 2014, Pile design and construction practice, CRC Press. 796

\section{Appendix A}

798 The numerical finite element analysis used in this paper is described in Figure 14. A vertical 799 axially-loaded pile is modelled with a series of linear-elastic two-noded beam elements with 800 vertical displacement degrees-of-freedom only and a series of nonlinear springs, 801 representing the surrounding soil, attached to each node. 
802 The behaviour of the soil spring is governed by a nonlinear load-transfer curve that follows

803 the Degradation and Hardening Hyperbolic Model (DHHM) model of (Pelecanos \& Soga 804 2017) described by Eq. 13.

805

$$
t=\frac{k_{m} z}{\sqrt[d]{\left(1+\left(\frac{k_{m}}{t_{m}} z\right)^{h d}\right)}}
$$

806 Eq. 13

807 Where $k_{m}$ is the maximum stiffness for displacement, $z=0$ (units: [force/length ${ }^{3}$ ]), $t_{m}$ is the

808 "maximum" value of shear stress, t (maximum only in the case of no hardening/softening, i.e.

$809 \mathrm{~h}=0$ ) (units: [force/length $\left.{ }^{2}\right]$ ), $\mathrm{d}$ is the degradation parameter (units: [-]), that governs the

810 degradation of subgrade modulus, $\mathrm{k}$, with displacement, $\mathrm{z}$, and $\mathrm{h}$ is the hardening parameter

811 (units: [-]), that mostly governs the model behaviour at large displacements, z. It should be

812 noted here that some t-z curves (see Section 1) include the effect of the pile diameter too,

813 but in the considered cases that mostly involved London Clay and large pile diameters (i.e.

814 no significant arching) it is expected that the diameter doesn't affect the obtained t-z curves.

815 The values of the 4 parameters of the model $\left(k_{m}, t_{m}, d, h\right)$ are obtained by matching the axial 816 strain, $\varepsilon_{a}(z)$, and vertical displacement, $u(z)$, profiles resulting from the numerical model and 817 those observed in the field as shown in Figure 6 (a) (c), Figure 9 (a) (c) and Figure 12 (a) (c).

818 The equations satisfying global equilibrium of the pile-soil problem follow a standard static 819 finite element formulation (Bathe 1996) and are described by Eq. 14.

820

$$
\left[K_{p}+K_{s}\right] \cdot\{u\}=\{F\}
$$

821 Eq. 14

822 Where, $\left[K_{p}\right]$ and $\left[K_{s}\right]$ are the global pile and soil stiffness matrices respectively, which contain 823 information about the geometry and the material properties of the pile and soil respectively, $824\{\mathrm{u}\}$ is the vector of the displacement degrees-of-freedom and $\{F\}$ is the vector of the 825 externally applied forces. 
826 Boundary conditions applied consist only of the applied load which is specified as a known

827 value in the $\{F\}$ vector; at the first node for a top-loaded pile or at the last node for a bottom-

828 loaded O-cell test. Finally, the numerical model parameters adopted for the analyses of the

829 case studies presented in this paper (which, as explained before, were obtained by matching

830 the observed pile response) are listed in Table 1.

831 Table 1. Parameters of the numerical FE beam-spring model for all cases considered

\begin{tabular}{|c|c|c|c|c|c|}
\hline \multicolumn{7}{|c|}{ Case 1 - Broadgate Pile } \\
\hline Layer & Depth [m] & $\mathbf{k}_{\mathrm{m}}\left[\mathrm{MN} / \mathrm{m}^{3}\right]$ & $\mathbf{t}_{\mathrm{m}}\left[\mathrm{MN} / \mathrm{m}^{2}\right]$ & $\mathbf{d}[]$ & $\mathbf{h}[]$ \\
\hline 1 & $0-6$ & 8 & 0.011 & 2 & 0.8 \\
\hline 2 & $6-12$ & 14 & 0.157 & 0.9 & 1.5 \\
\hline 3 & $12-19$ & 16 & 0.136 & 2.5 & 1 \\
\hline 4 & $19-25$ & 2 & 0.008 & 1.2 & 1 \\
\hline Base & 25 & 459 & 65573 & 1 & 1 \\
\hline
\end{tabular}

Case 2 - East Village Pile

\begin{tabular}{|c|c|c|c|c|c|}
\hline Layer & Depth [m] & $\mathbf{k}_{\mathbf{m}}\left[\mathrm{MN} / \mathbf{m}^{3}\right]$ & $\mathbf{t}_{\mathbf{m}}\left[\mathrm{MN} / \mathbf{m}^{2}\right]$ & $\mathbf{d}[]$ & $\mathbf{h ~ [ ]}$ \\
\hline 1 & $0-14$ & 14 & 0.053 & 1 & 1 \\
\hline 2 & $14-23$ & 37 & 0.223 & 1 & 1 \\
\hline 3 & $23-32$ & 24 & 0.195 & 1.6 & 1 \\
\hline Base & 32 & 513 & 17.113 & 1 & 1 \\
\hline
\end{tabular}

Case 3 - Francis Crick Pile

\begin{tabular}{|c|c|c|c|c|c|}
\hline Layer & Depth [m] & $\mathbf{k}_{\mathbf{m}}\left[\mathrm{MN} / \mathbf{m}^{3}\right]$ & $\mathbf{t}_{\mathbf{m}}\left[\mathrm{MN} / \mathbf{m}^{2}\right]$ & $\mathbf{d}[]$ & $\mathbf{h}[]$ \\
\hline 1 & $0-21$ & 21 & 0.036 & 3 & 1 \\
\hline 2 & $1-25$ & 57 & 0.117 & 3 & 0.7 \\
\hline
\end{tabular}

832 


\section{Appendix B}

834 The data used for the API (2002) curves shown in Figure 7, Figure 10, Figure 13 are listed in 835 Table 2. These curves depend only on the soil material properties and the geometry 836 (diameter, D) of the pile. The values for tult were obtained by using Eq. 9 and Eq. 10 for clay 837 and sand respectively, whereas those for qult were obtained by using Eq. 11 and Eq. 12 for clay and sand respectively.

Table 2. Data used for the API (2002) curves.

\begin{tabular}{|l|l|l|l|l|l|l|l|l|l|}
\hline \multicolumn{7}{|c|}{ t-z for sand } \\
\hline z [in] & 0 & 0.1 & 0.4 & & & & & \\
\hline t/tult [-] & 0 & 1 & 1 & & & & & \\
\hline \multicolumn{7}{|c|}{ t-z for clay } & & \\
\hline z/D [-] & 0 & 0.0016 & 0.0031 & 0.0057 & 0.008 & 0.01 & 0.02 & 0.03 \\
\hline t/tult [-] & 0 & 0.3 & 0.5 & 0.75 & 0.9 & 1 & 0.9 & 0.9 \\
\hline & & & & & & & \\
\hline
\end{tabular}

840

\section{$841 \quad$ Figure Captions}

842 Figure 1. Principle of distributed fibre optic sensing using BOTDR.

843 Figure 2. Fibre optic cables used at the pile cases studied: (a) Fujikura reinforced 844 "strain cable" and (b) Unitube "temperature cable".

845 Figure 3. Schematic illustration of FO installation and monitoring of piled foundations.

846 Figure 4. View of installed fibre optic cables and vibrating wire strain gauges on the 847 pile cage: (a) detailed view of clamp, (b) general view of installed sensors.

848 Figure 5. Description of Case 1 - Broadgate pile load test case: (a) pile geometry \& 849 soil stratigraphy, (b) test schedule

850 Figure 6. Monitored data profiles for Case 1 - Broadgate: (a) axial strain, (b) axial 851 force and (c) vertical displacement. 
852 Figure 7. Calculated pile shaft friction from FE analysis for Case 1 - Broadgate: (a) 853 shaft friction profiles, (b) shaft friction development with applied load, (c) shaft 854 friction development with vertical displacement, and (d) relevant API t-z and q-z 855 curves.

856 Figure 8. Description of Case 2 - East Village pile load test case: (a) pile geometry \& 857 soil stratigraphy, (b) test schedule

858 Figure 9. Monitored data profiles for Case 2 - East Village: (a) axial strain, (b) axial 859 force and (c) vertical displacement.

860 Figure 10. Calculated pile shaft friction from FE analysis for Case 2 - East Village: (a) 861 shaft friction profiles, (b) shaft friction development with applied load, (c) shaft 862 friction development with vertical displacement, and (d) relevant API t-z and q-z 863 curves.

864 Figure 11. Description of Case 3 - Francis Crick pile load test case: (a) pile geometry 865 \& soil stratigraphy, (b) test schedule

866 Figure 12. Monitored data profiles for Case 3 - Francis Crick: (a) axial strain, (b) axial 867 force and (c) vertical displacement.

868 Figure 13. Calculated pile shaft friction from FE analysis for Case 3 - Francis Crick: 869 (a) shaft friction profiles, (b) shaft friction development with applied load, (c) shaft 870 friction development with vertical displacement, and (d) relevant API t-z curves.

871 Figure 14. Numerical analysis model of pile-soil interaction: (a) pile, (b) axial strain 872 distribution, (c) top load-displacement, (d) numerical beam-spring model and (e) load873 transfer curve. 


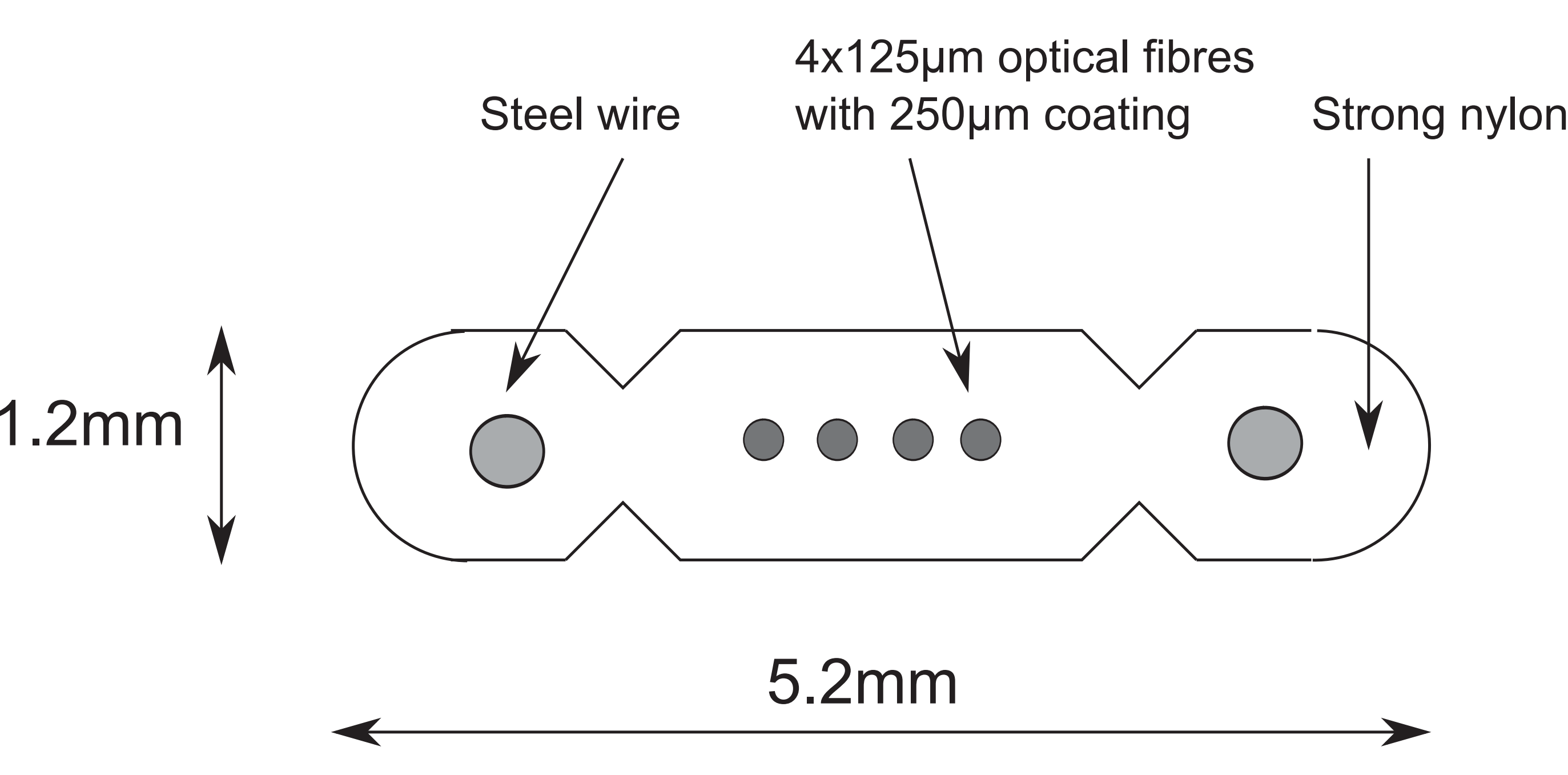


Click here to download Figure Fig_02b.eps $\stackrel{ \pm}{\underline{*}}$

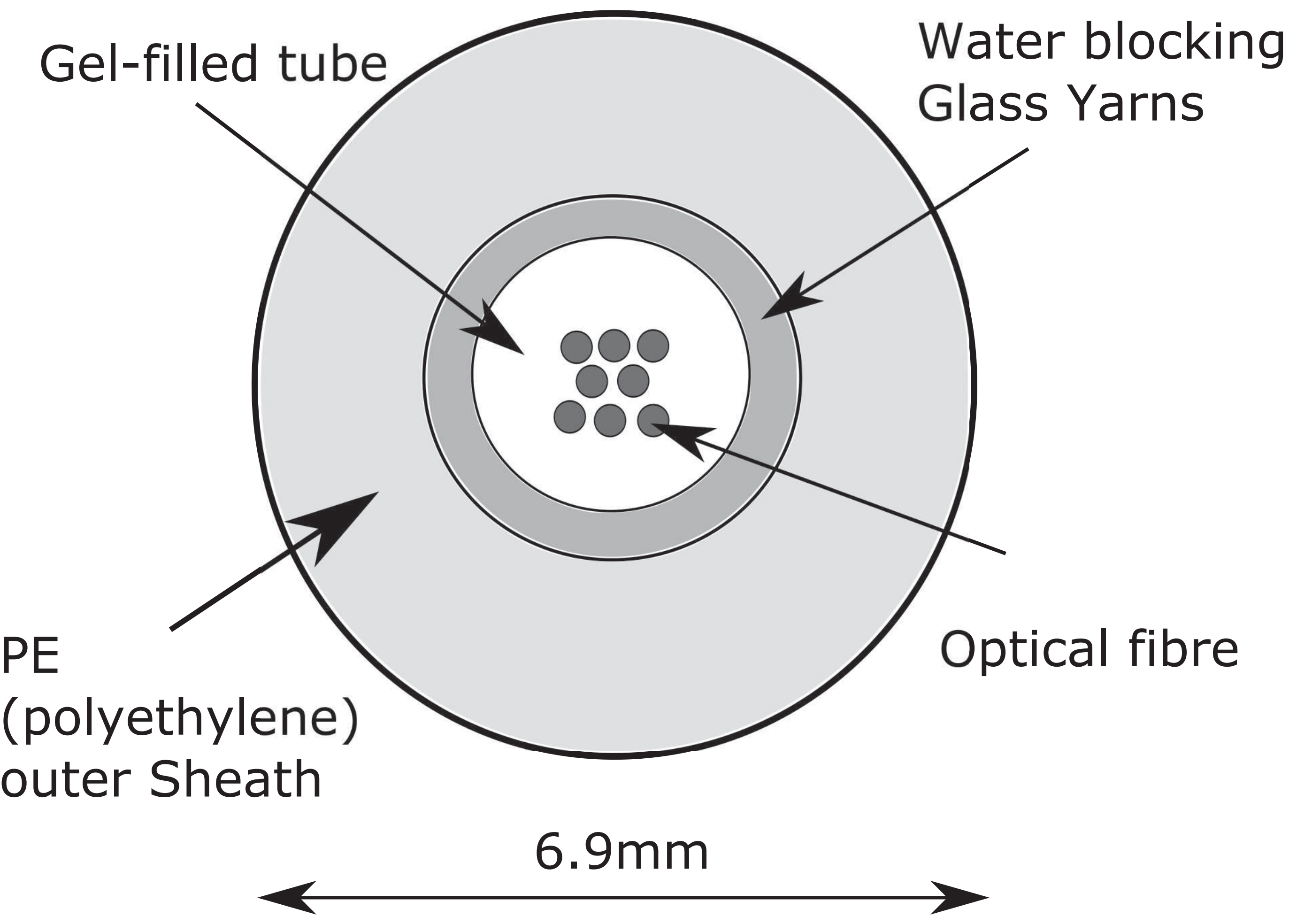


Click here to download Figure Fig_04a.tif $\underline{\underline{ }}$

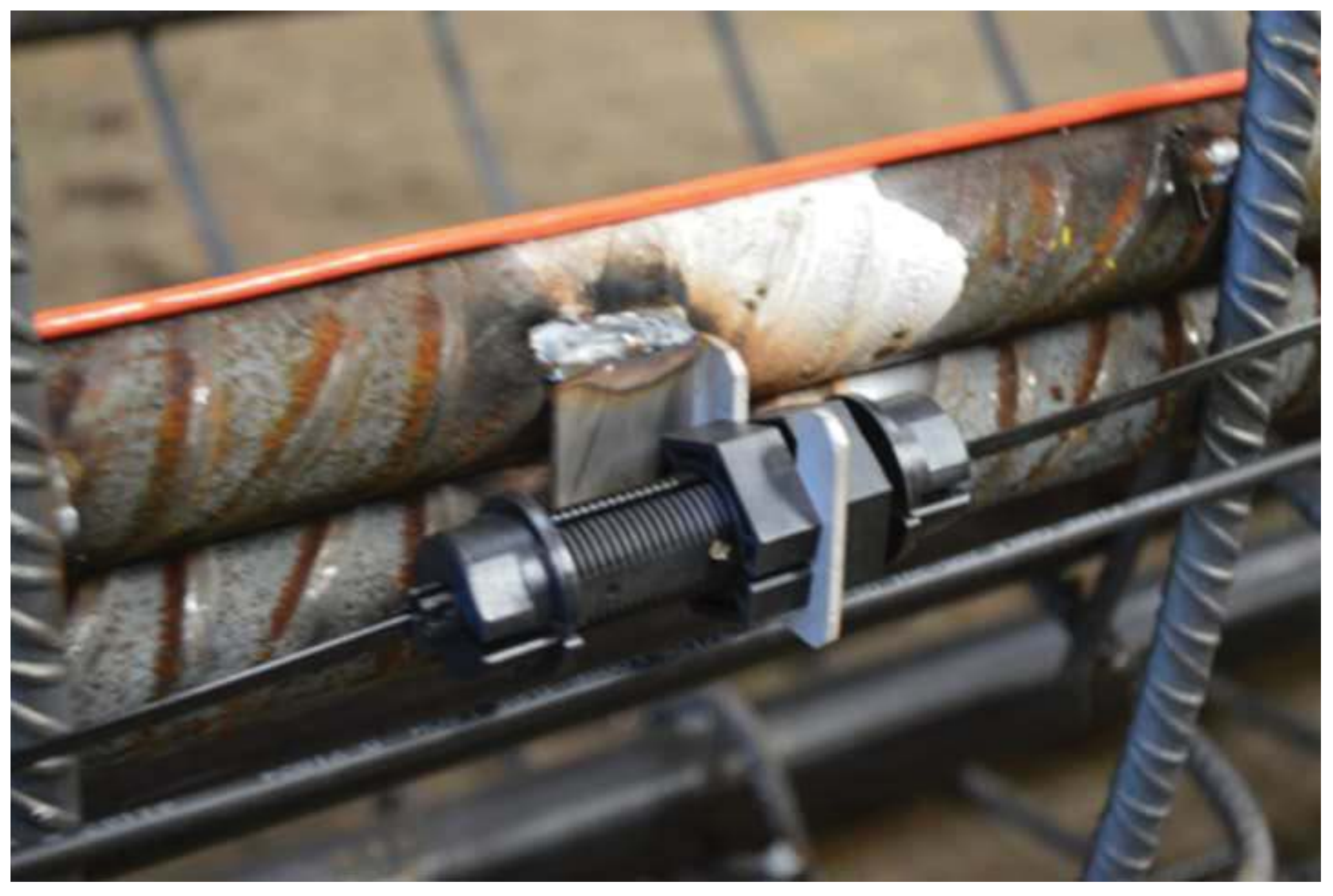




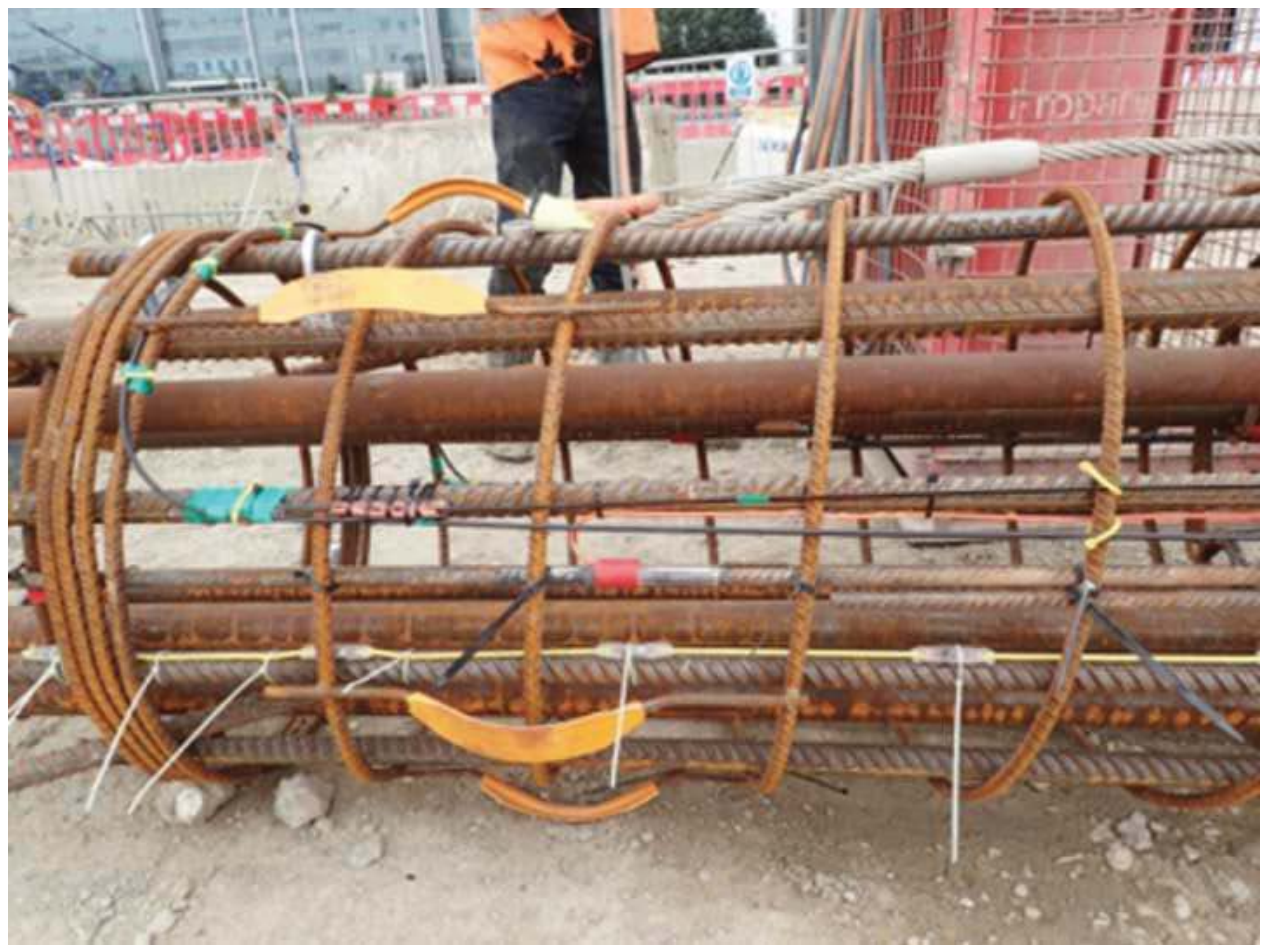




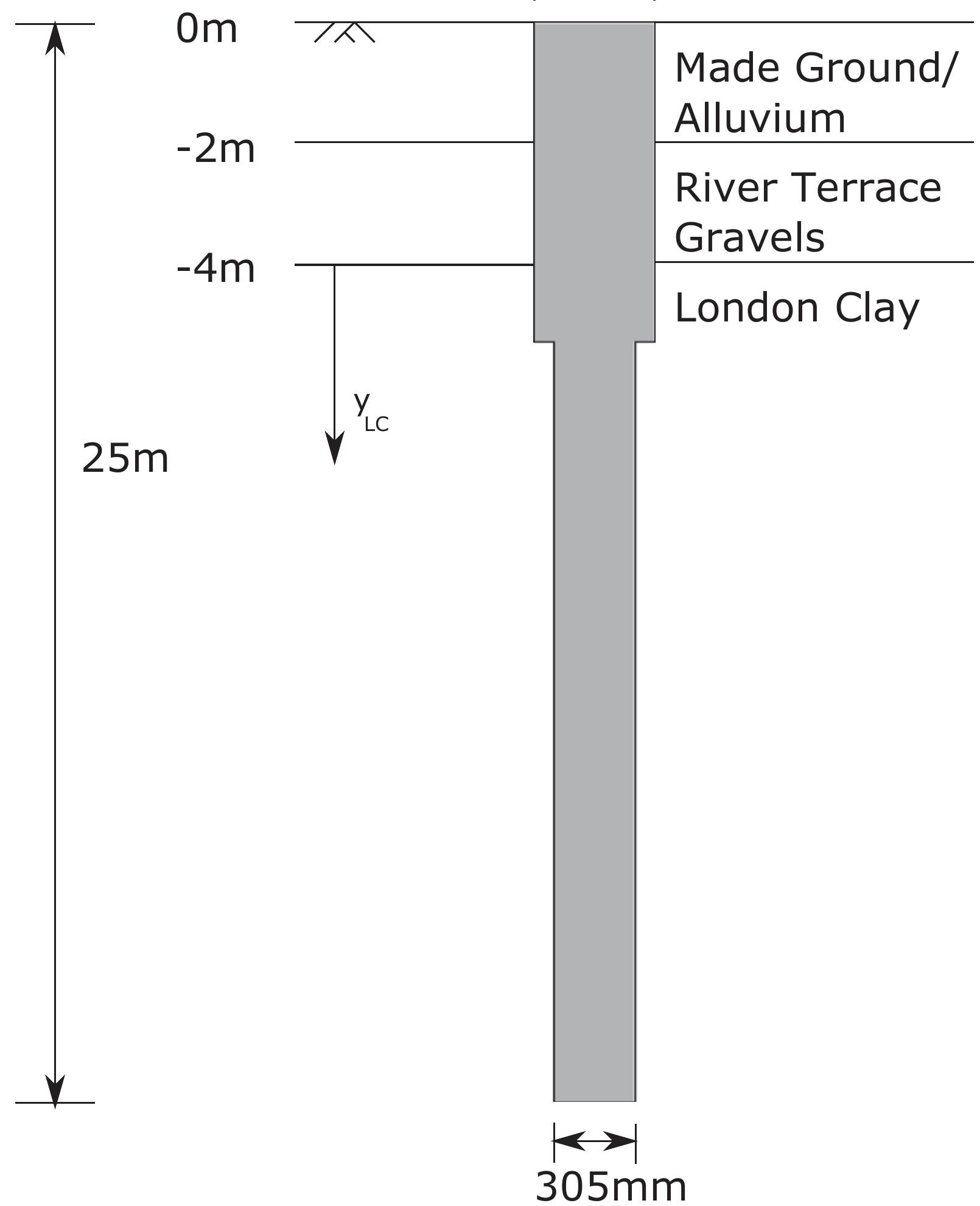




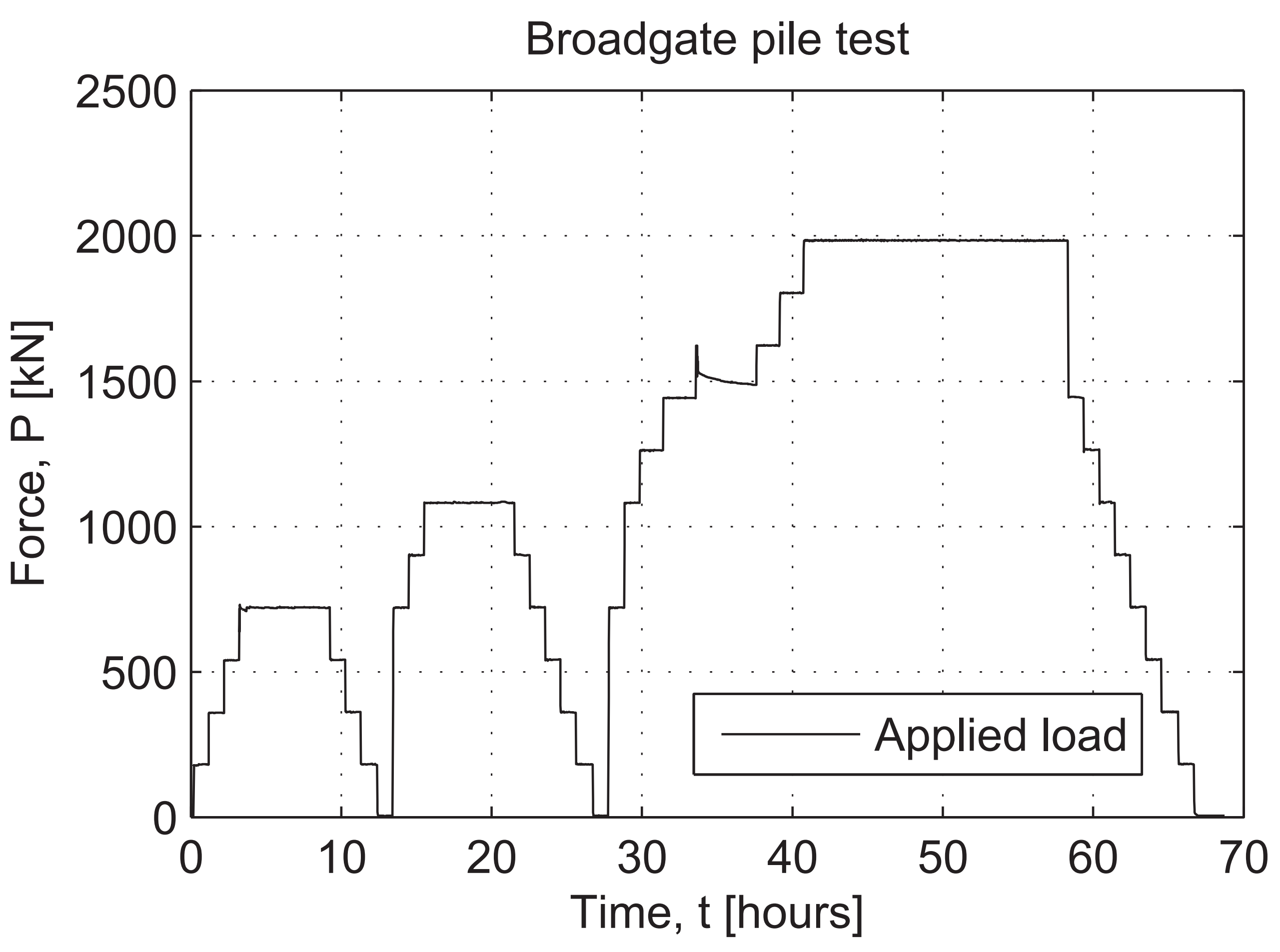



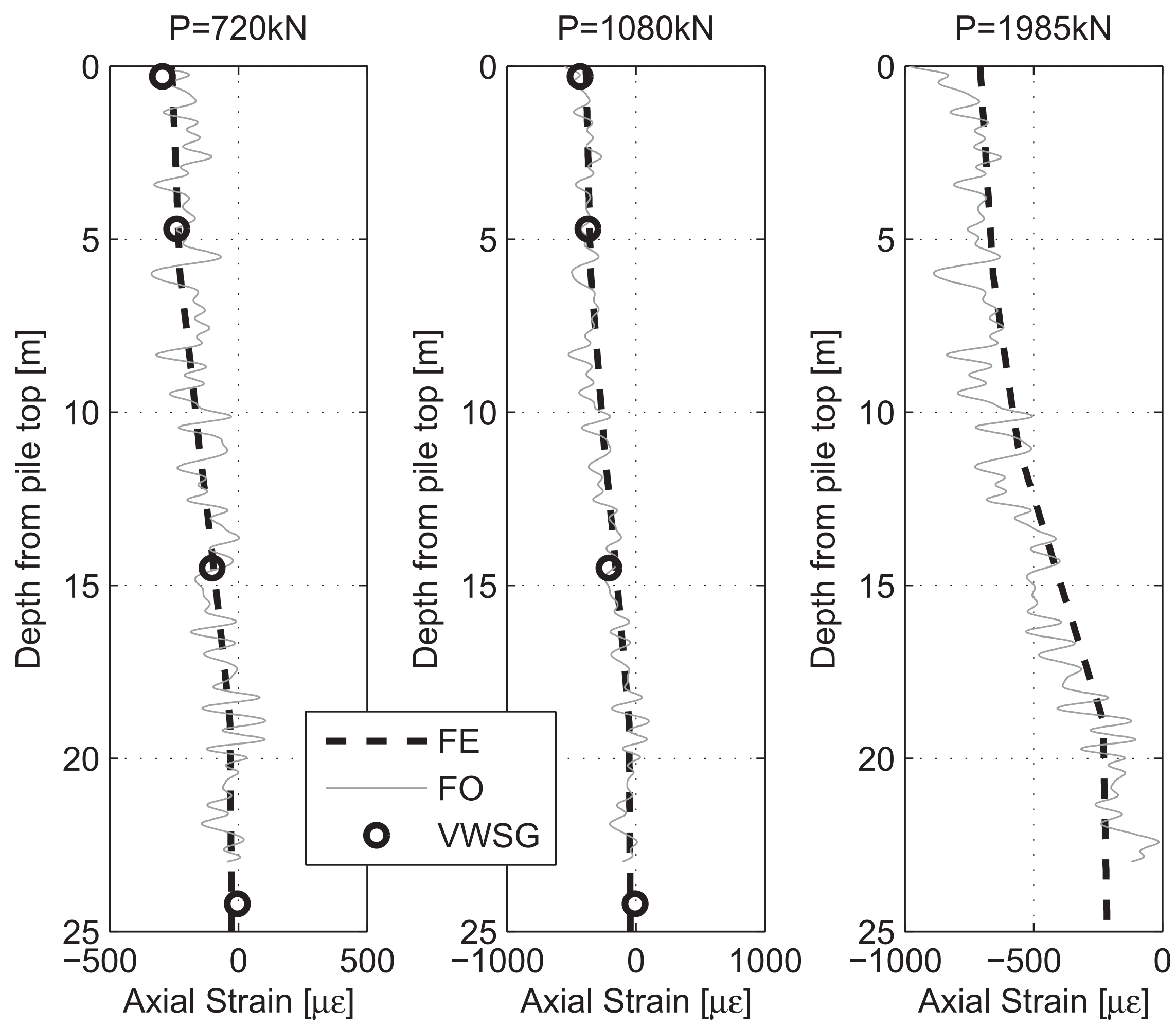

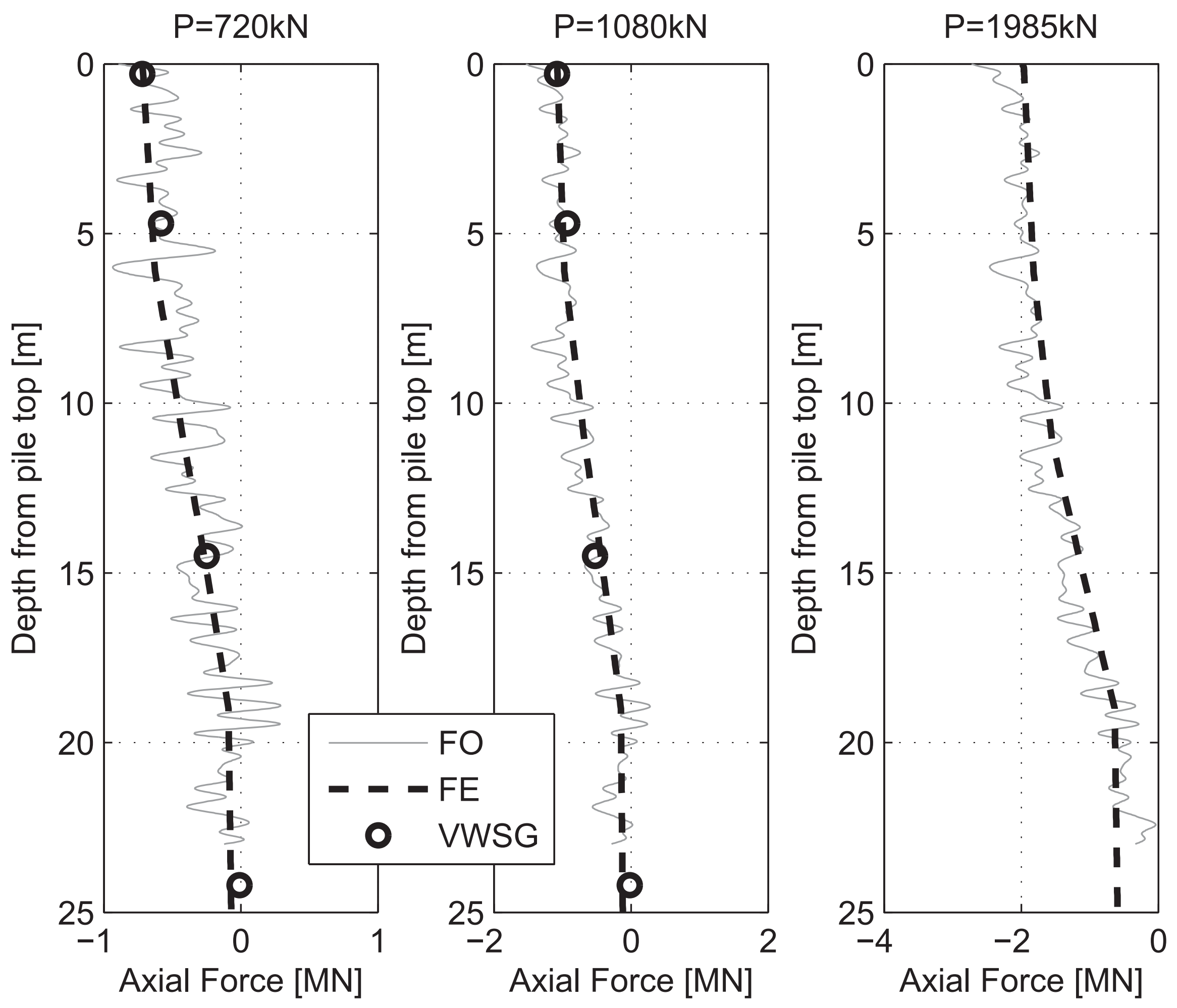

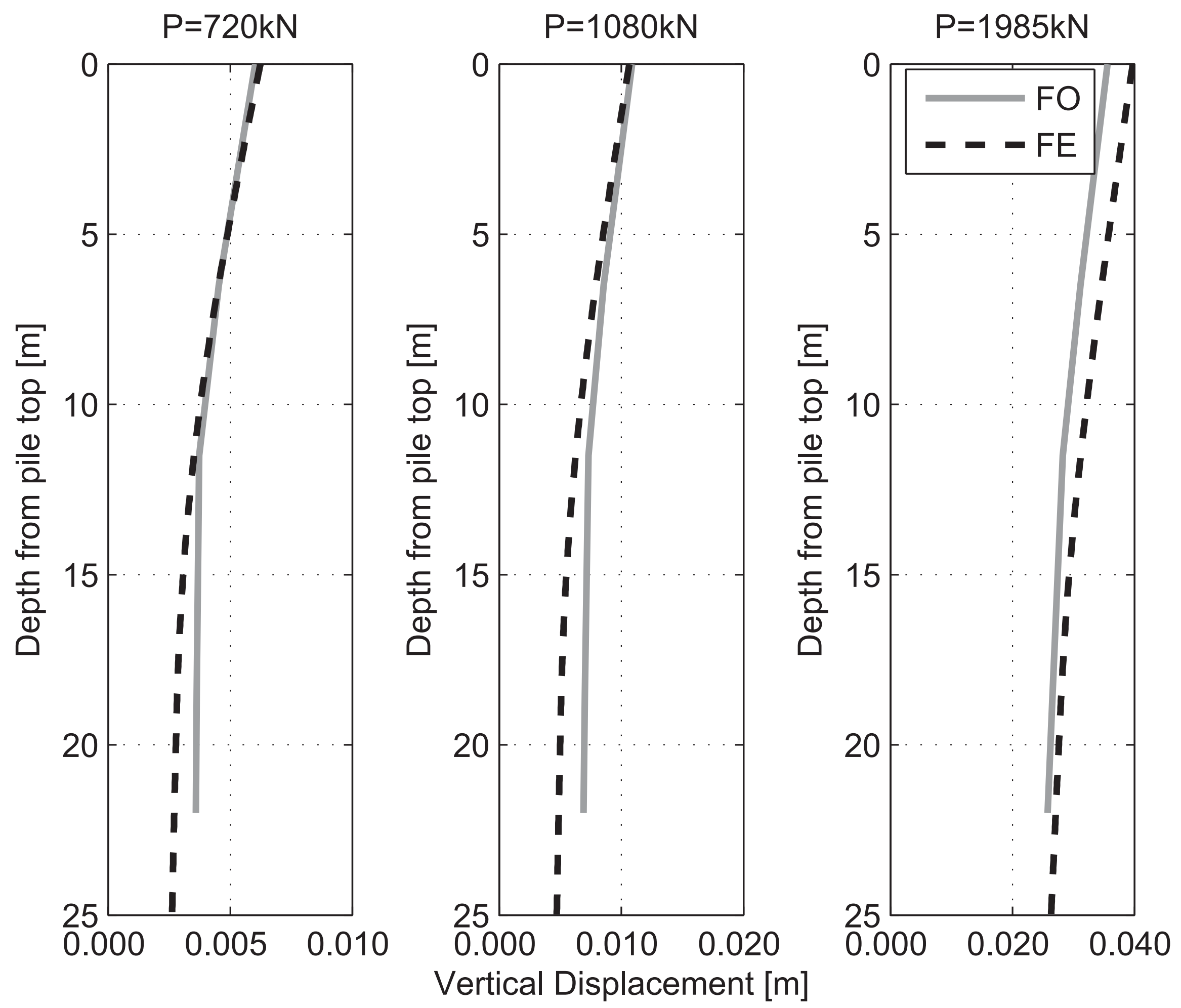

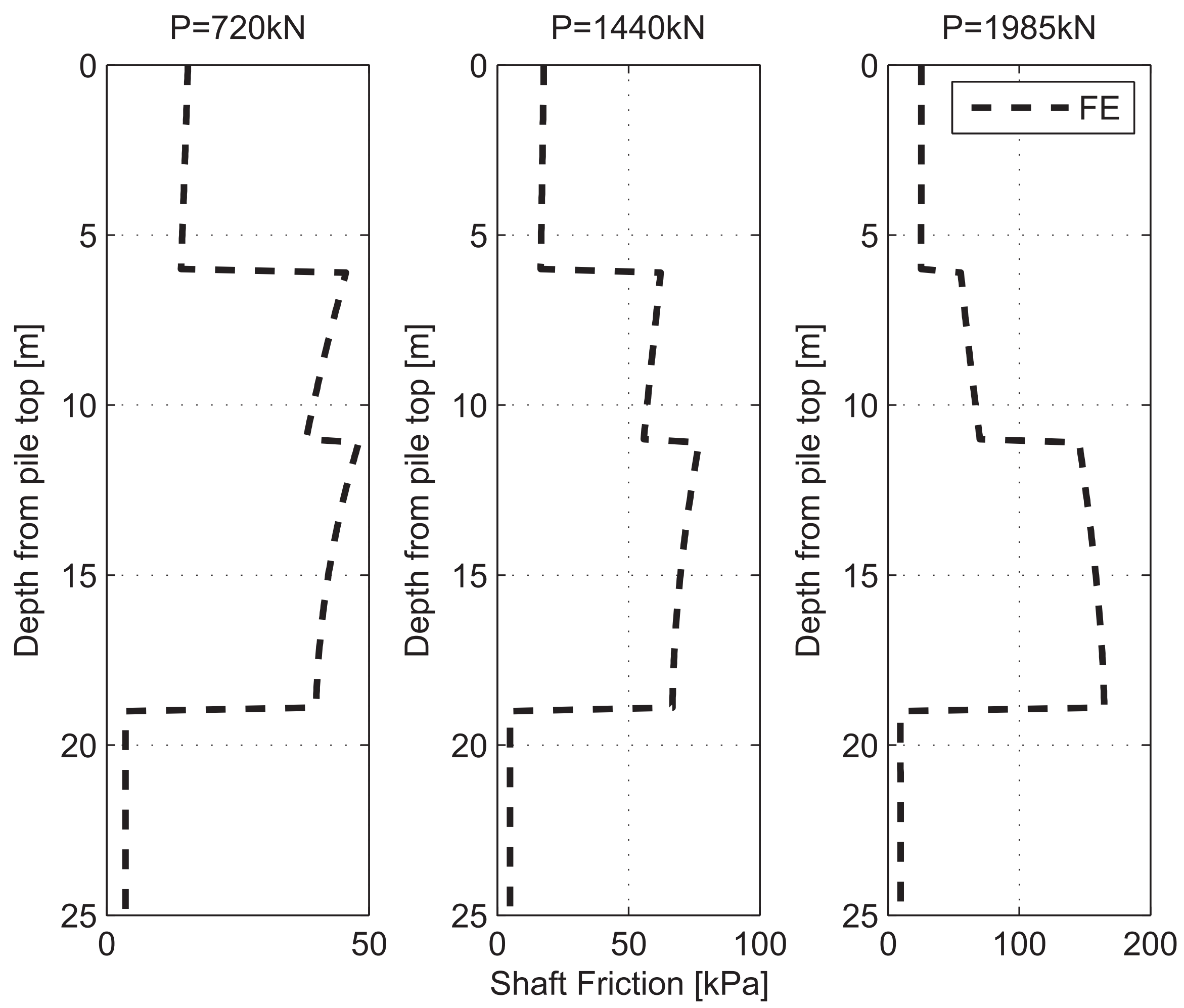


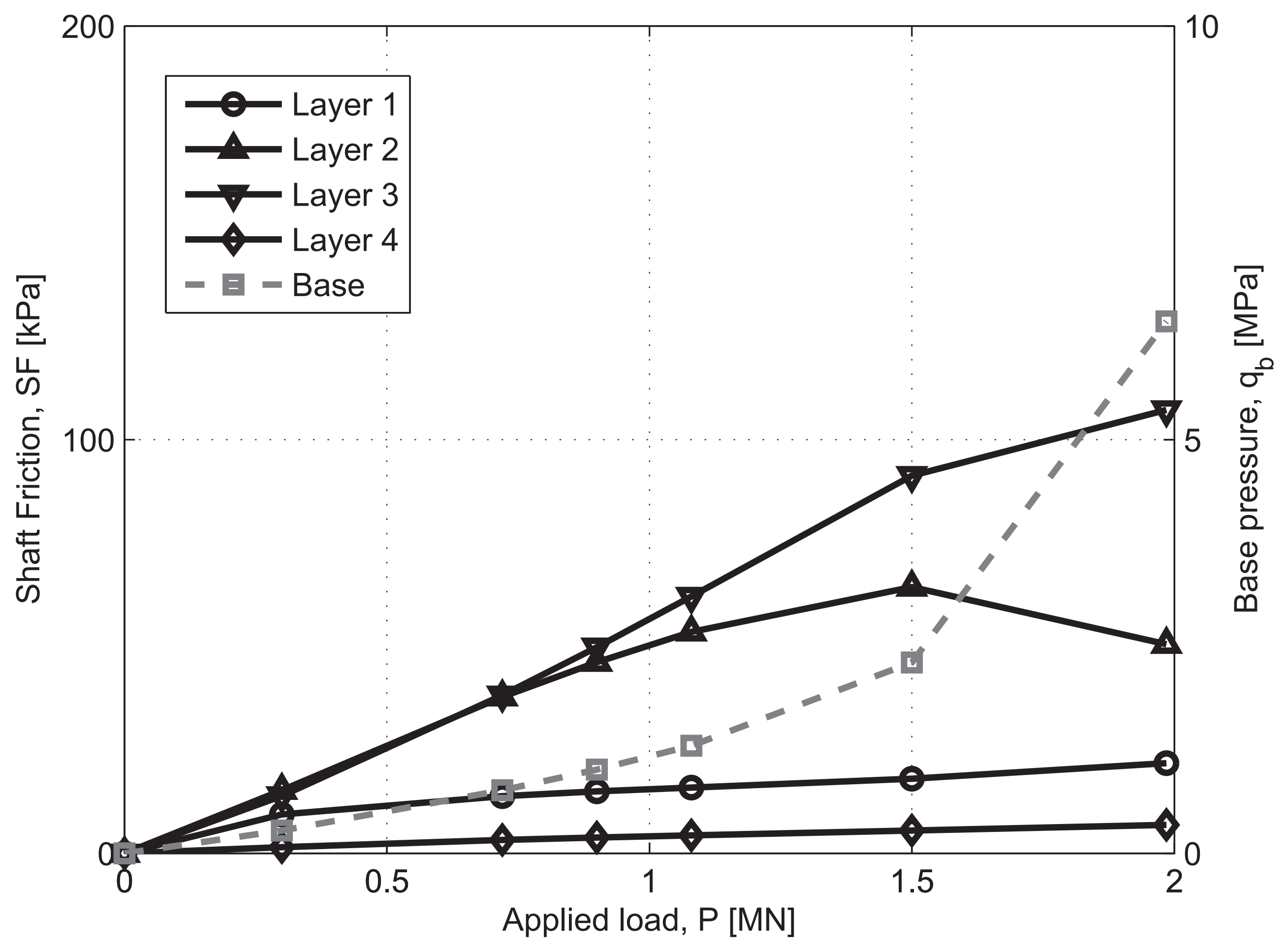




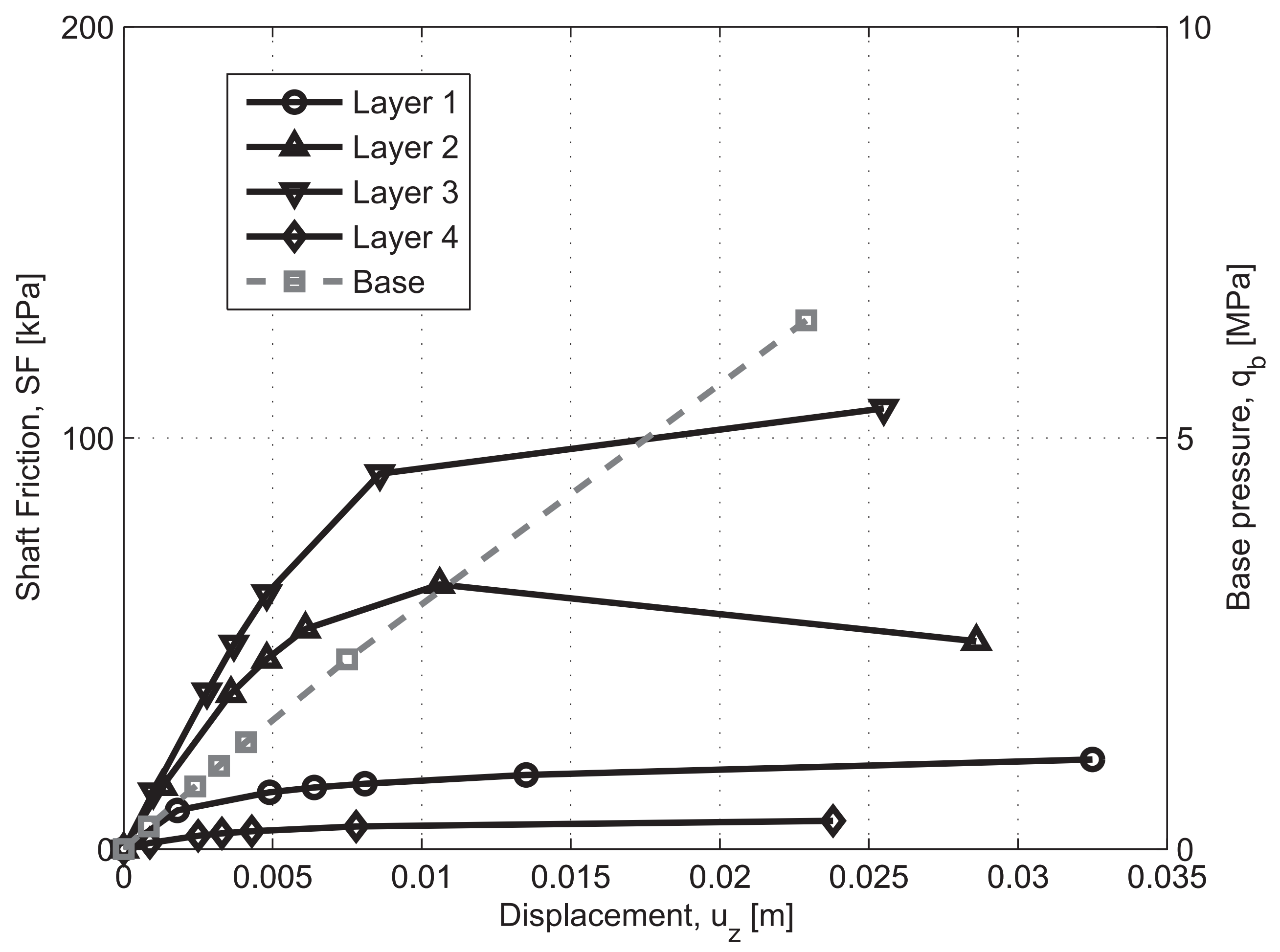


Click here to download Figure Fig_07d.eps $\stackrel{\star}{ \pm}$

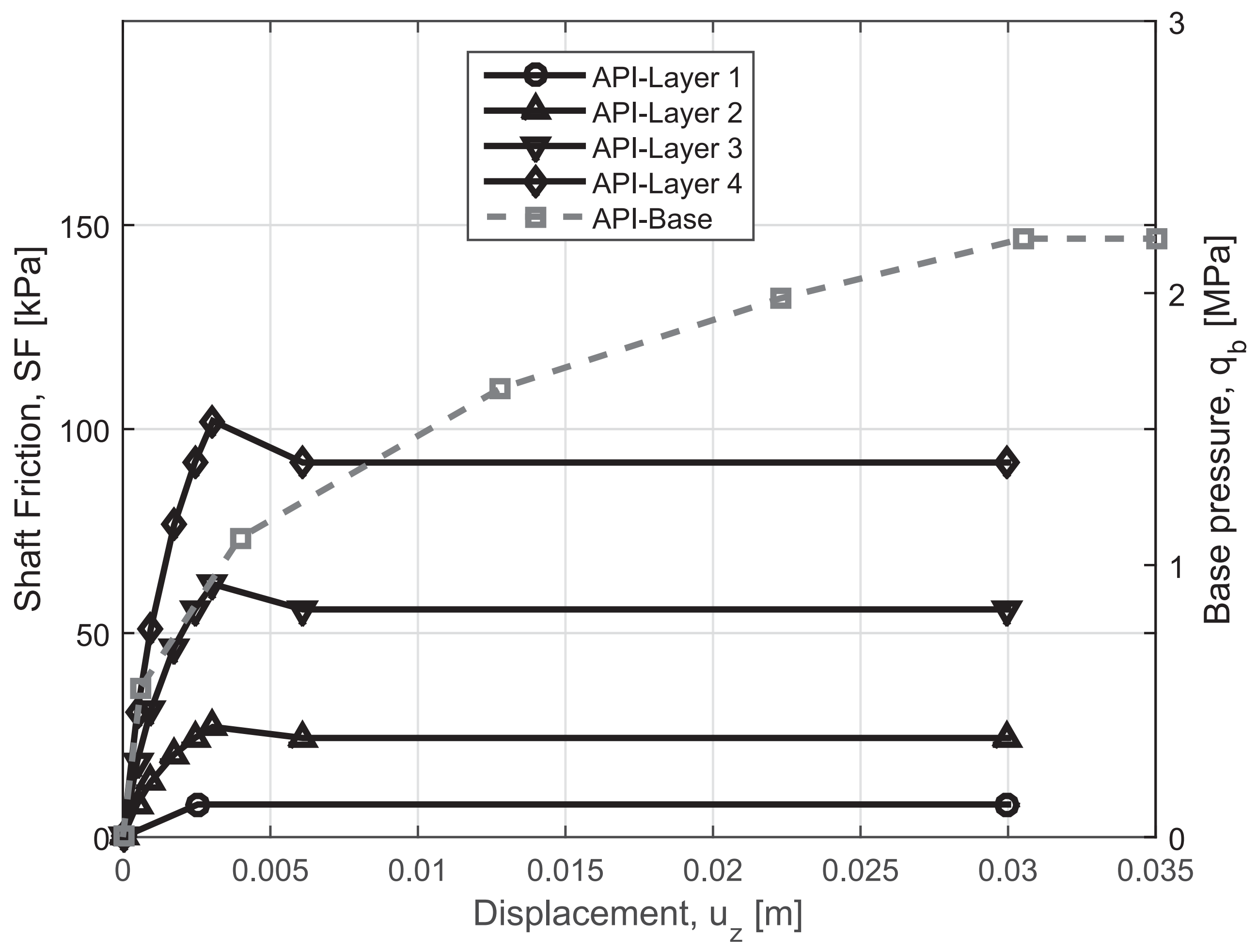




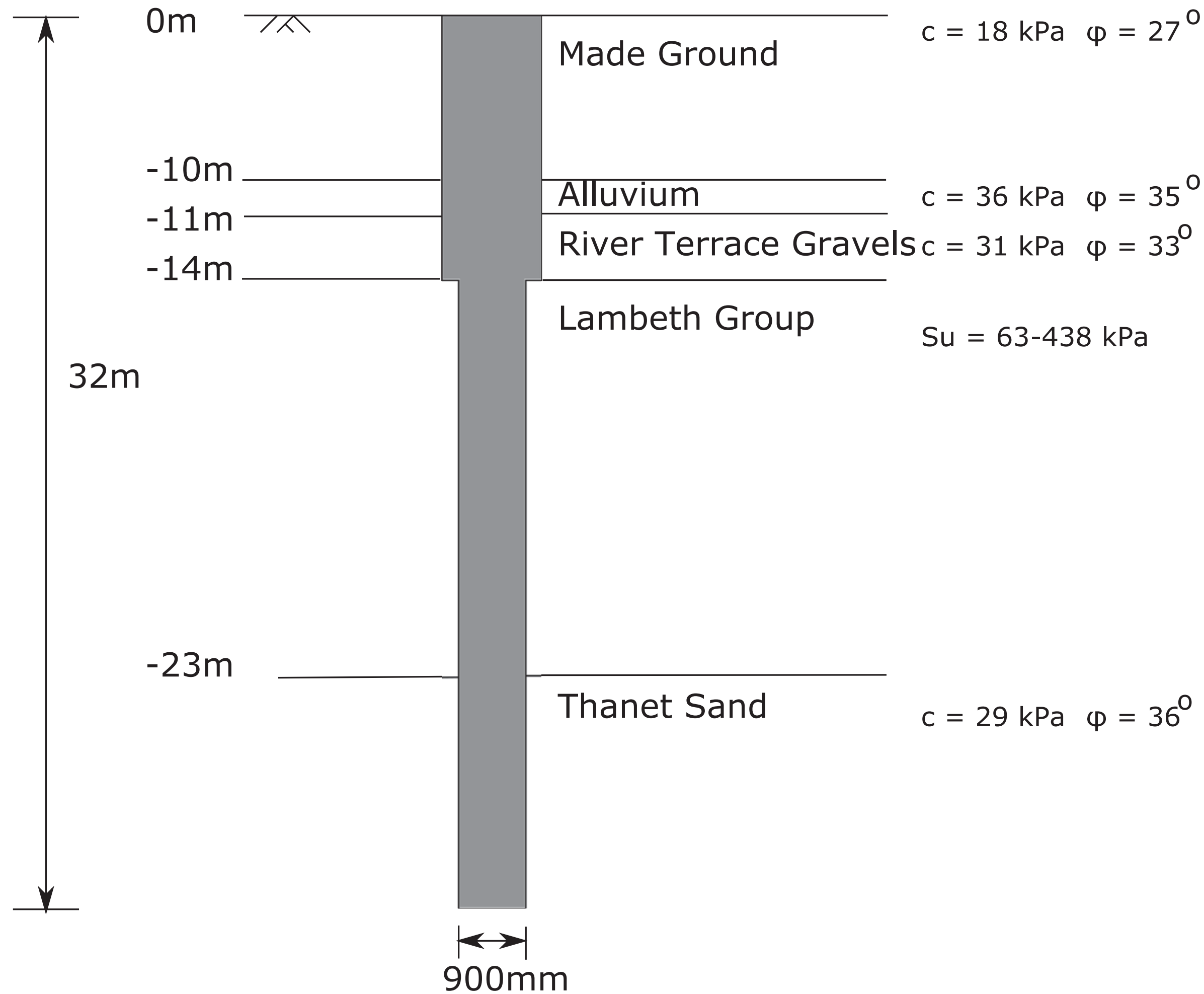


Click here to download Figure Fig_08b.eps $\underline{\underline{\Perp}}$

East Village pile test

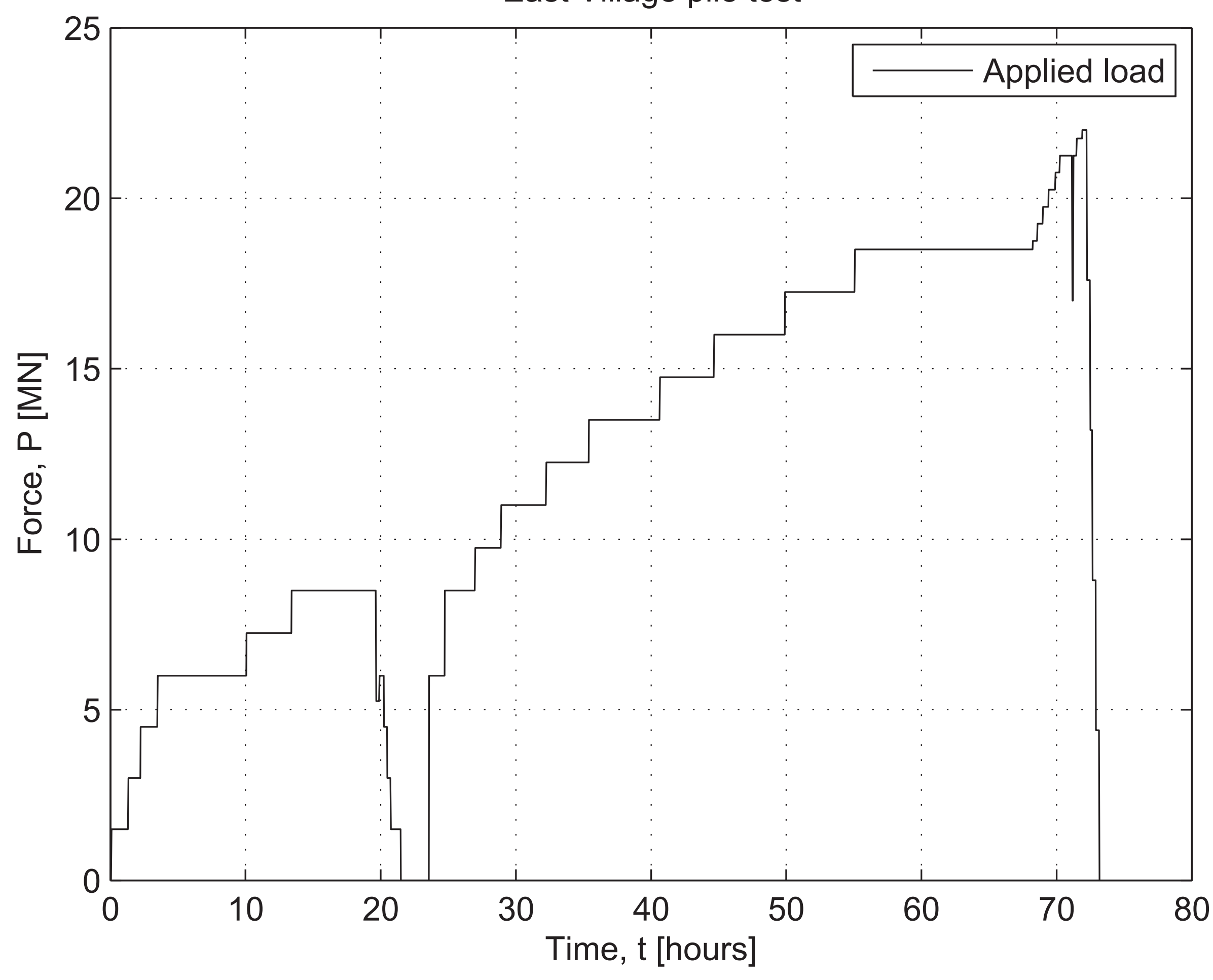



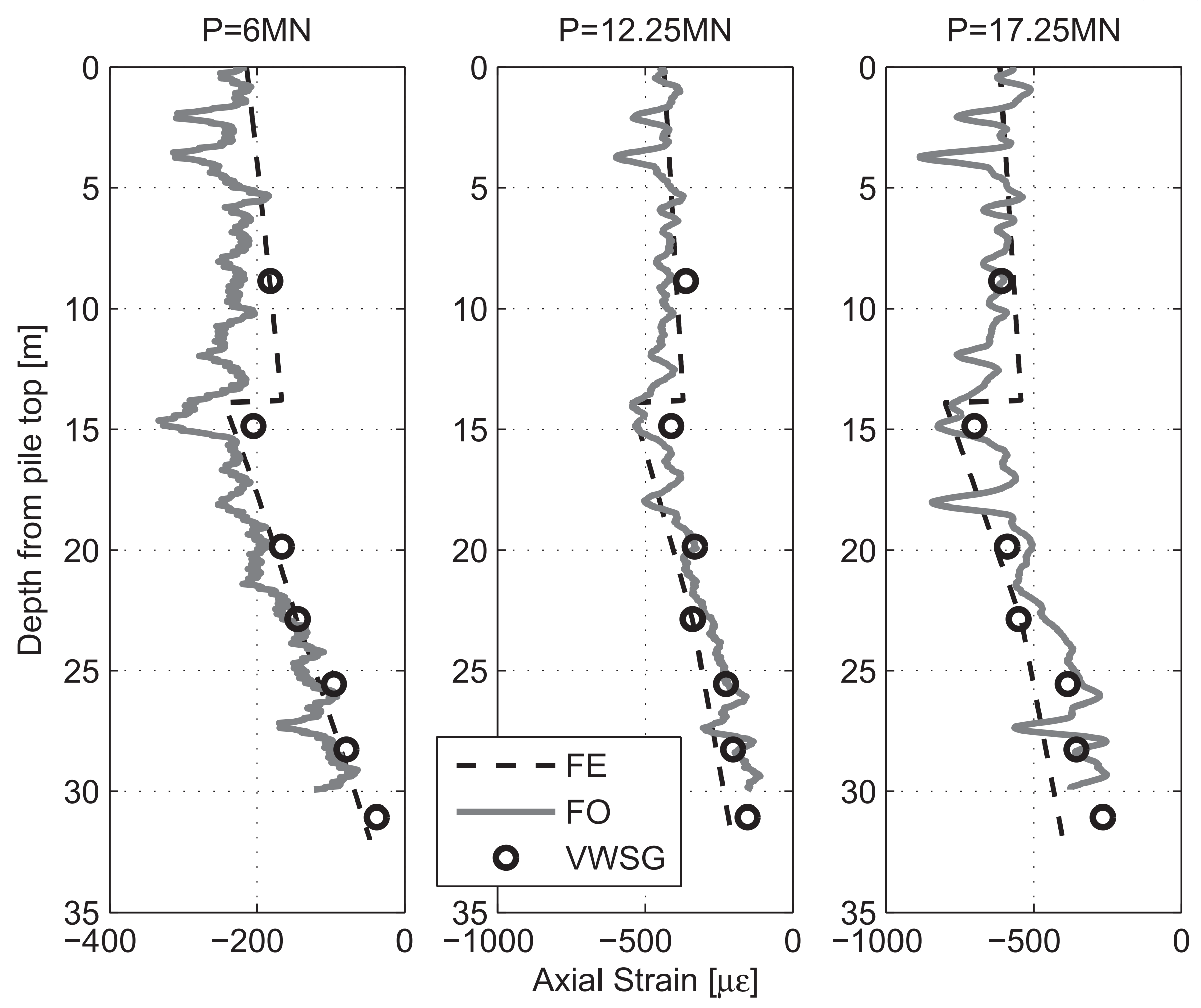

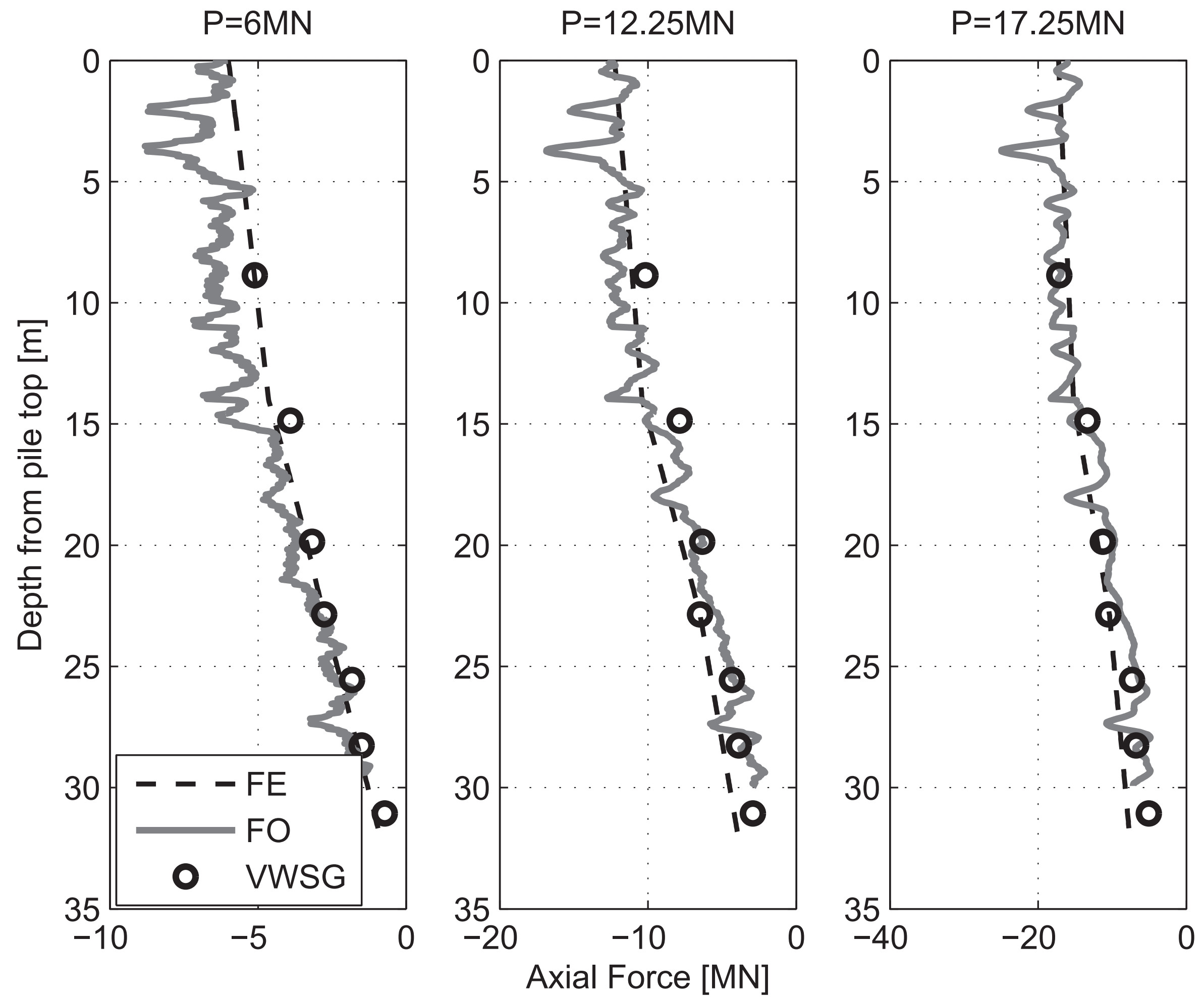

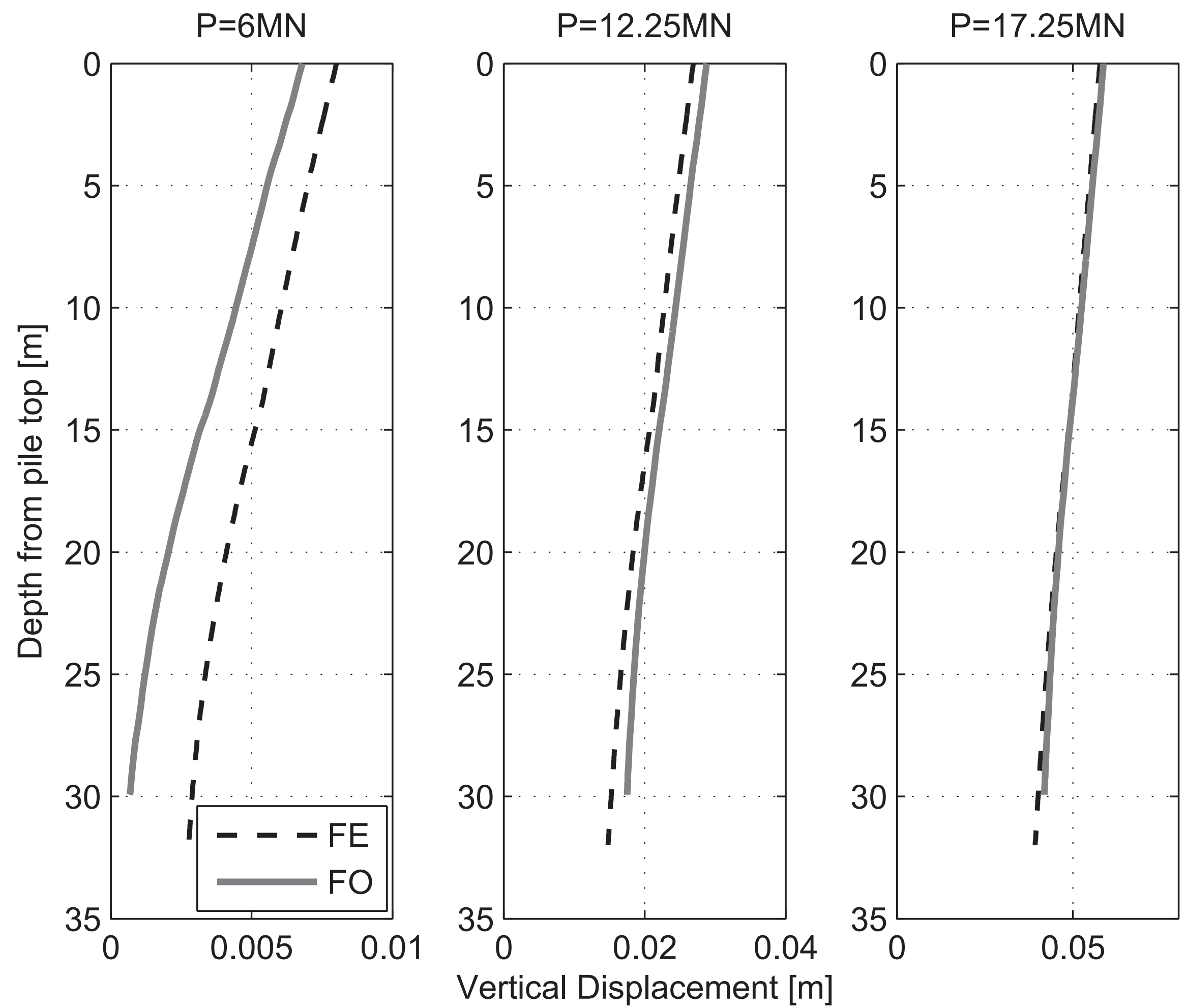

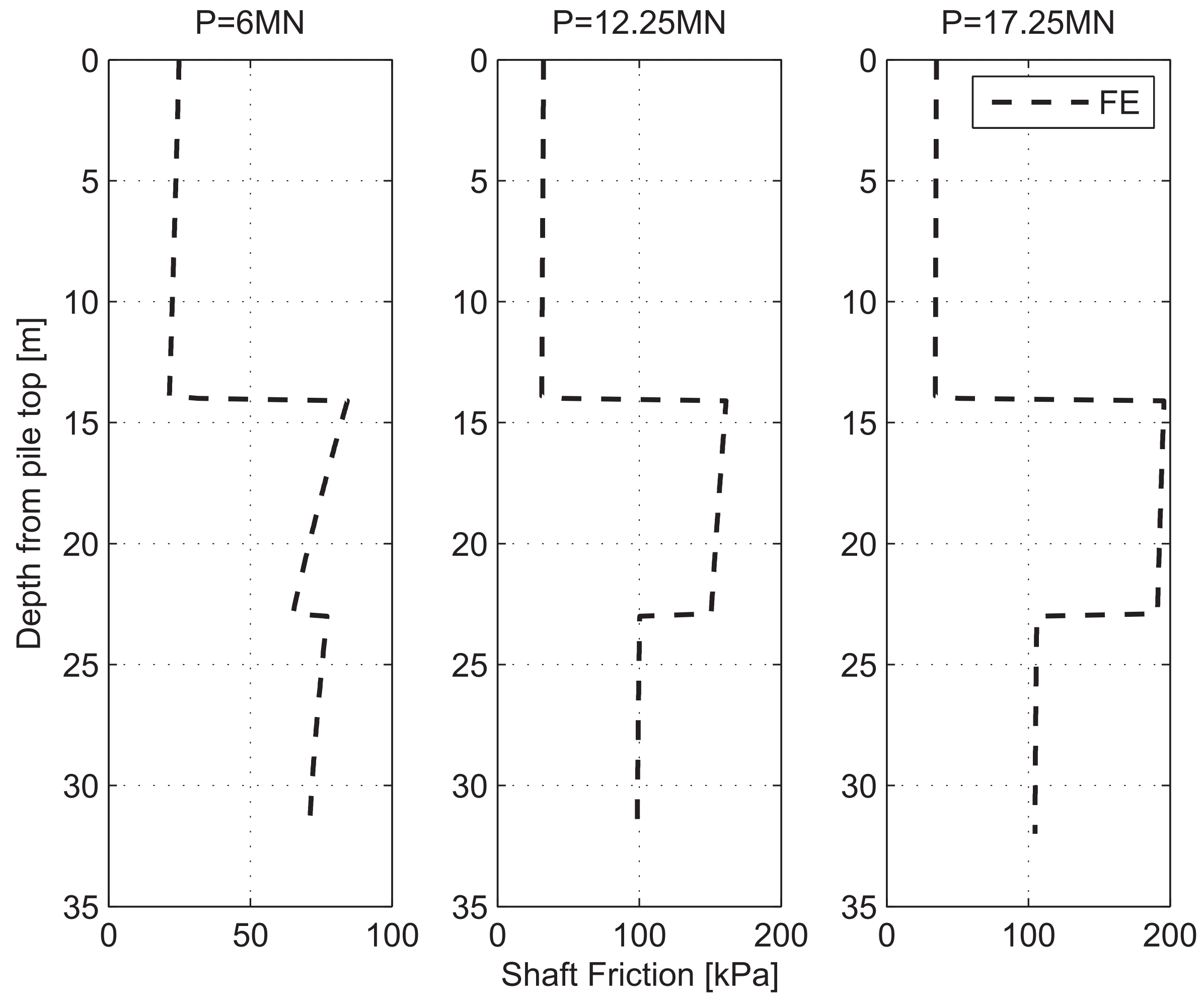
Click here to download Figure Fig_10b.eps $\stackrel{ \pm}{*}$

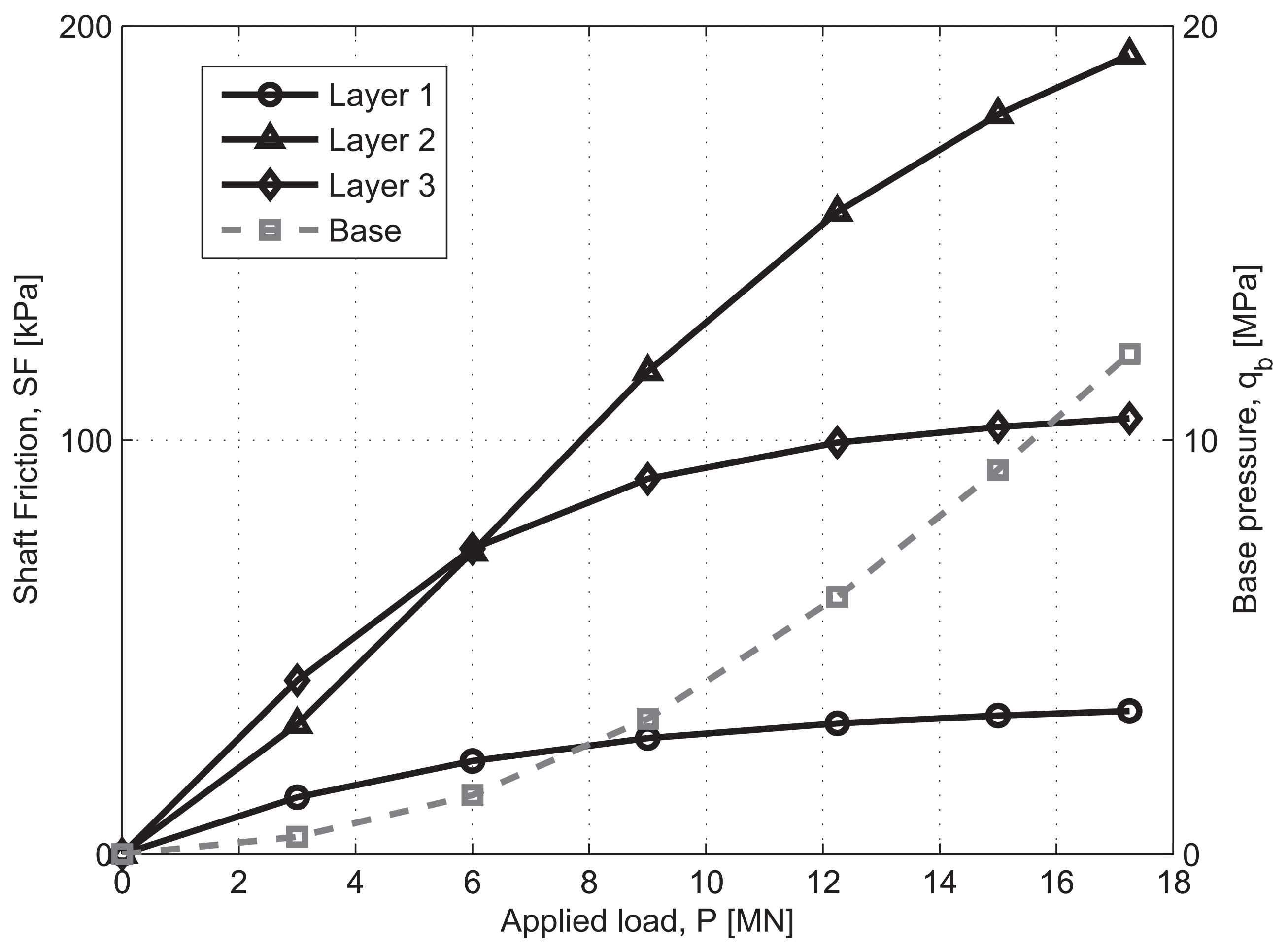


Click here to download Figure Fig_10c.eps $\stackrel{ \pm}{*}$

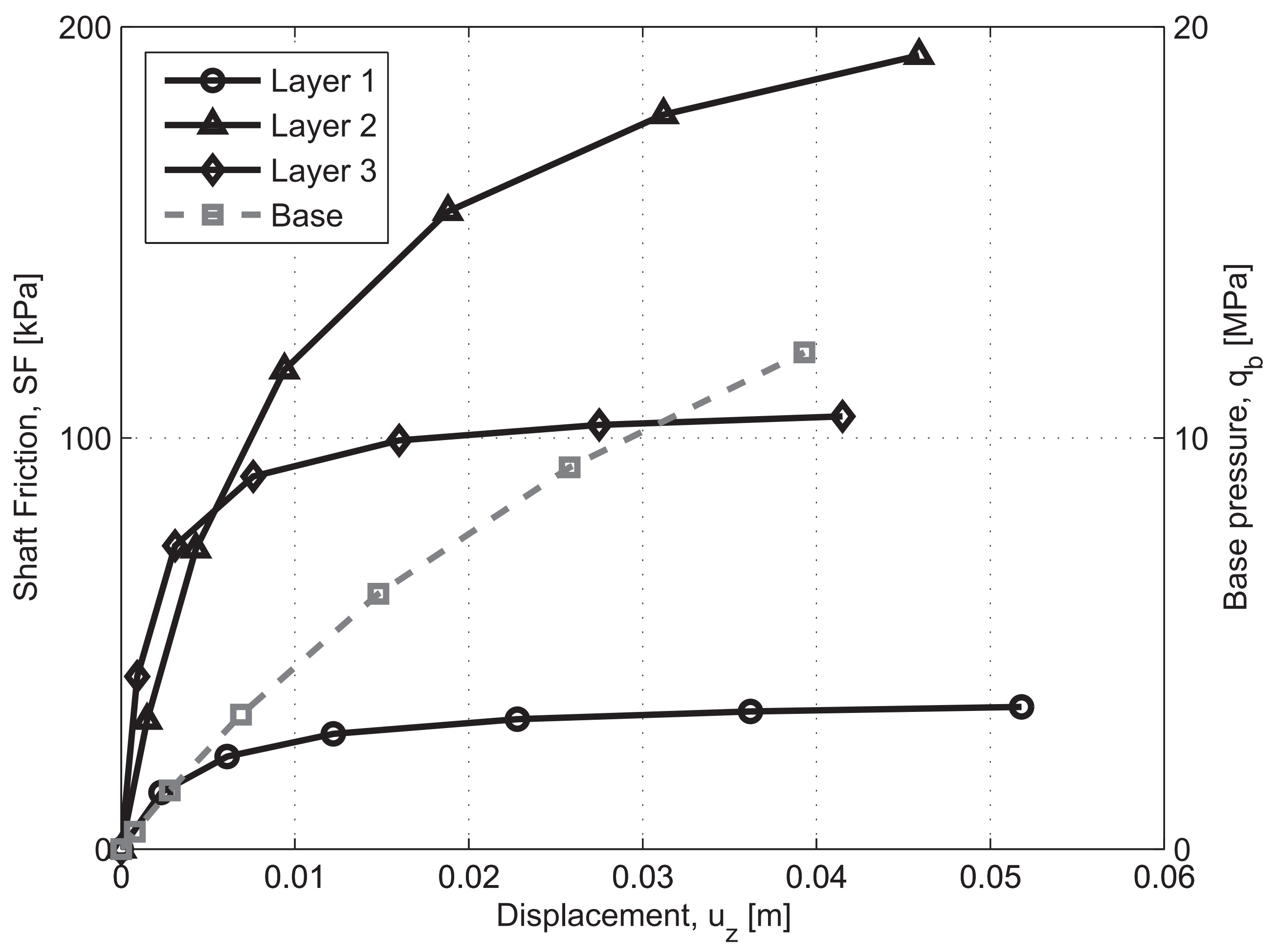




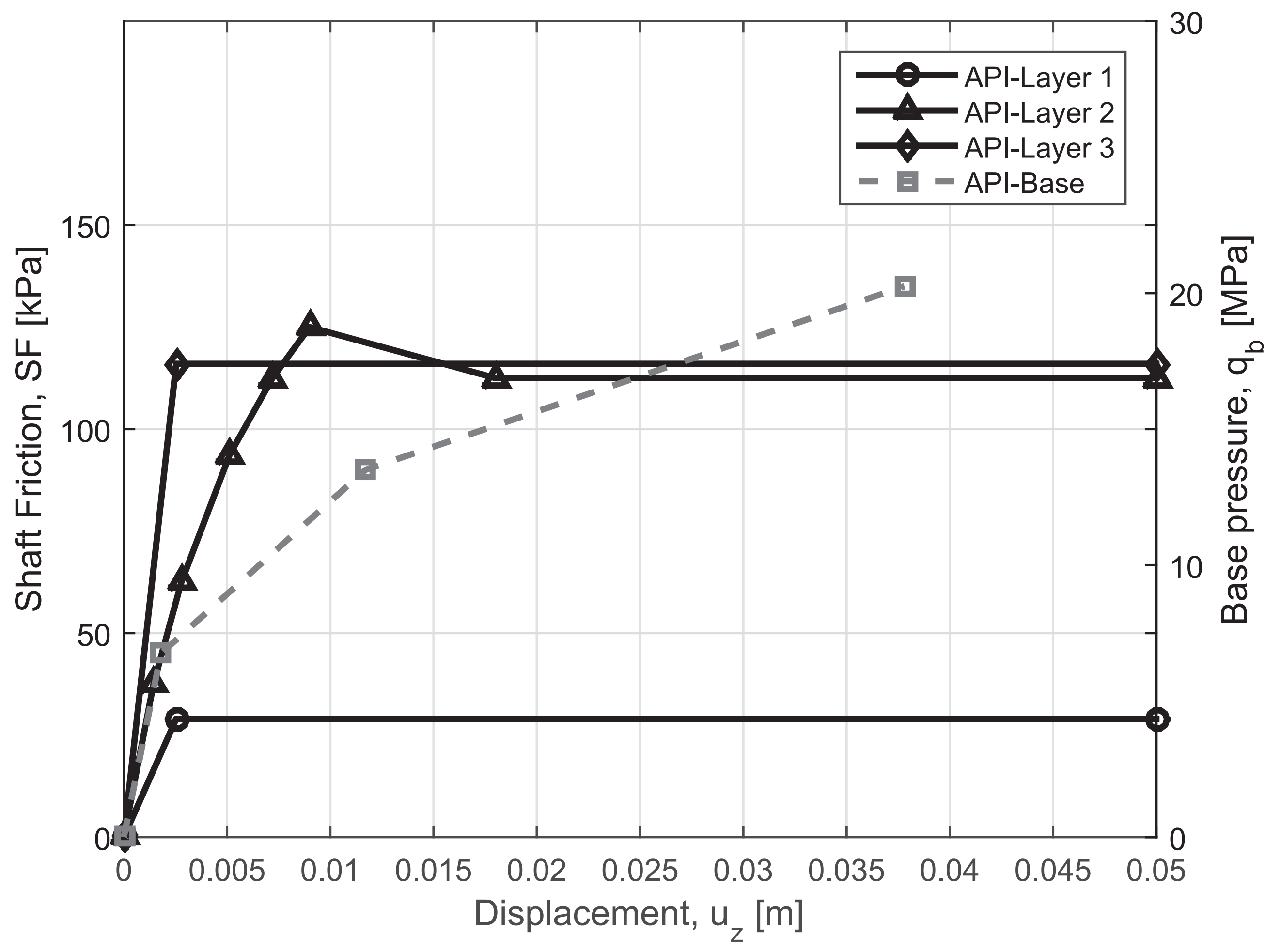


Click here to download Figure Fig_11b.eps $\underline{\underline{ \pm}}$

Francis Crick pile test

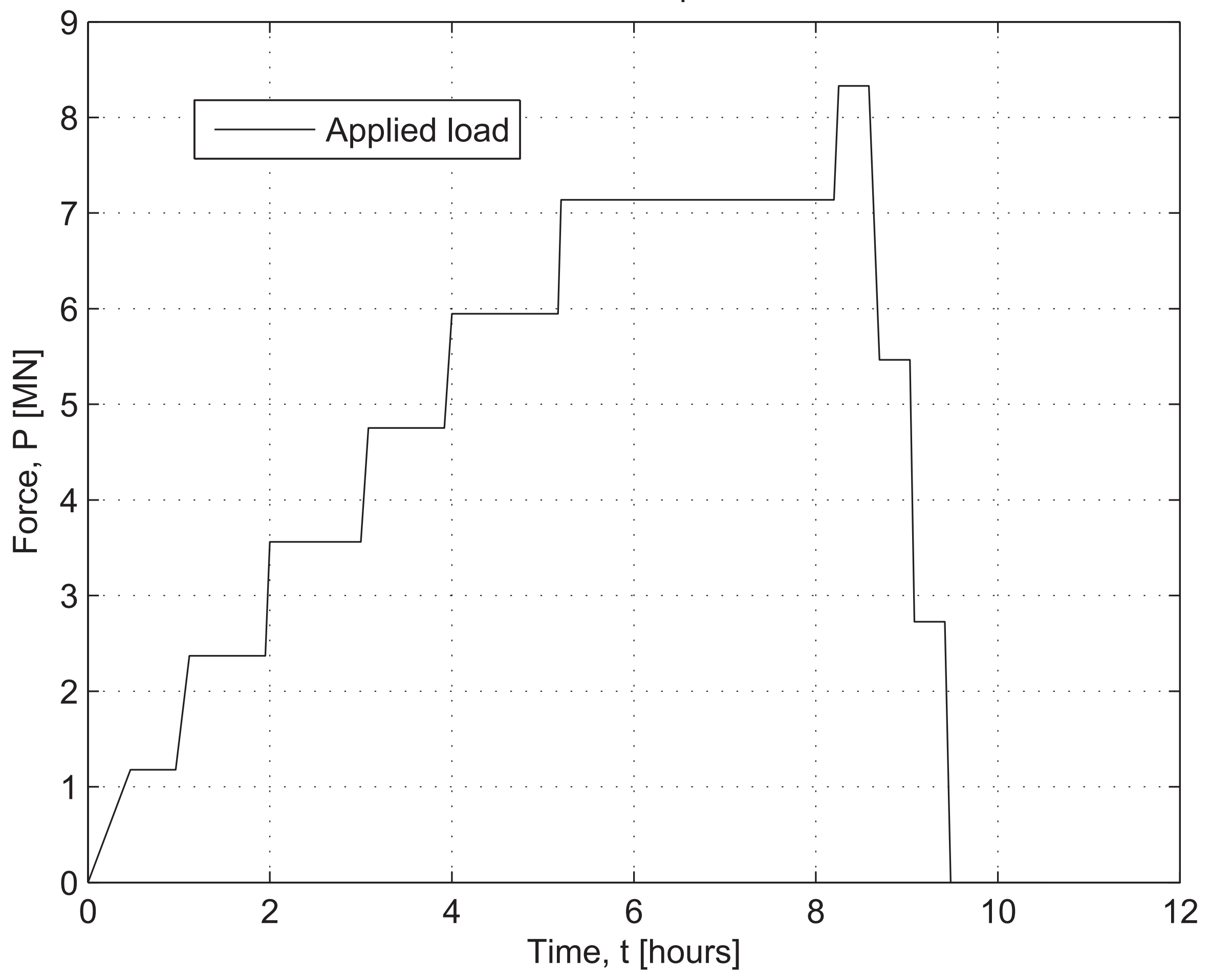




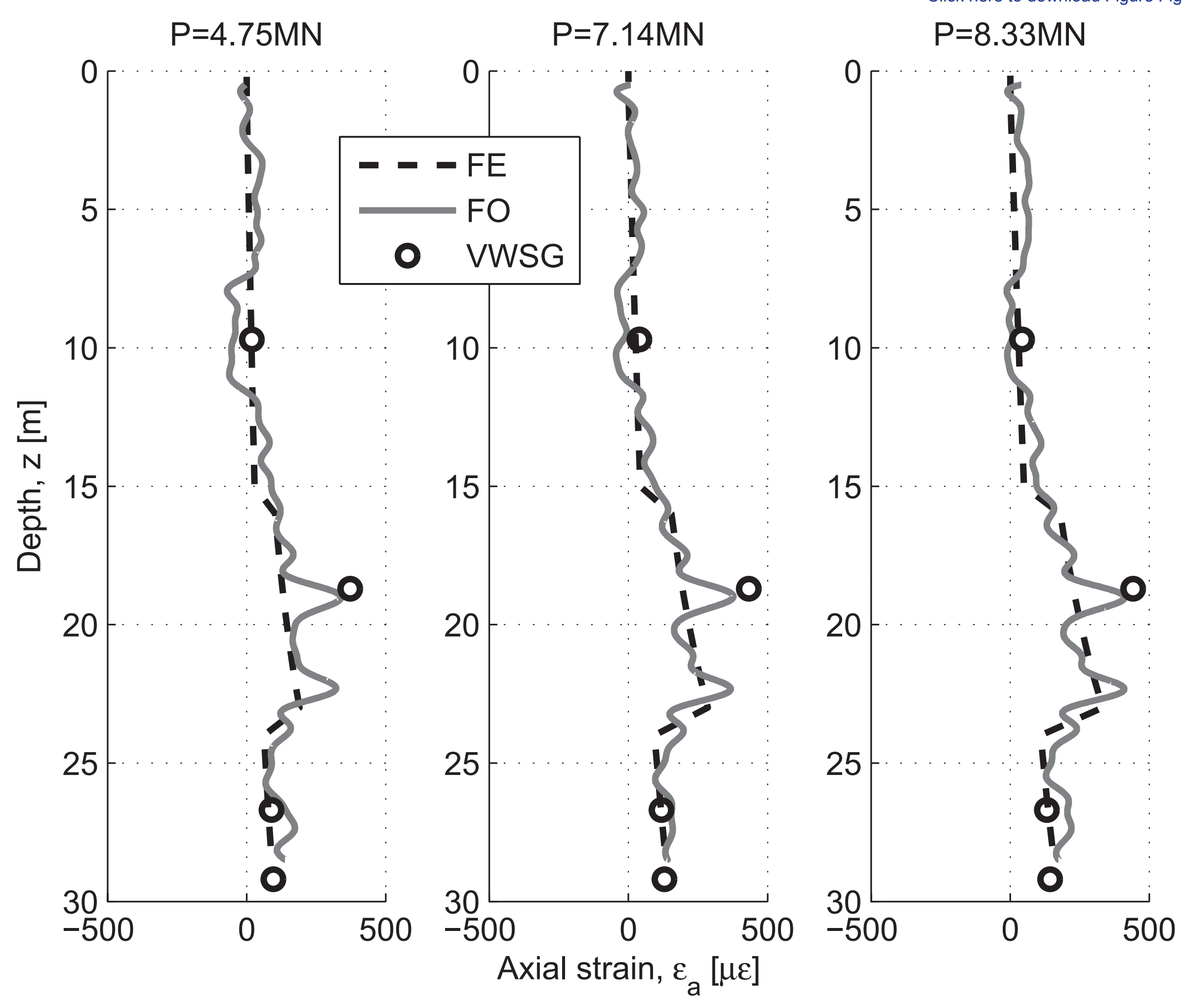




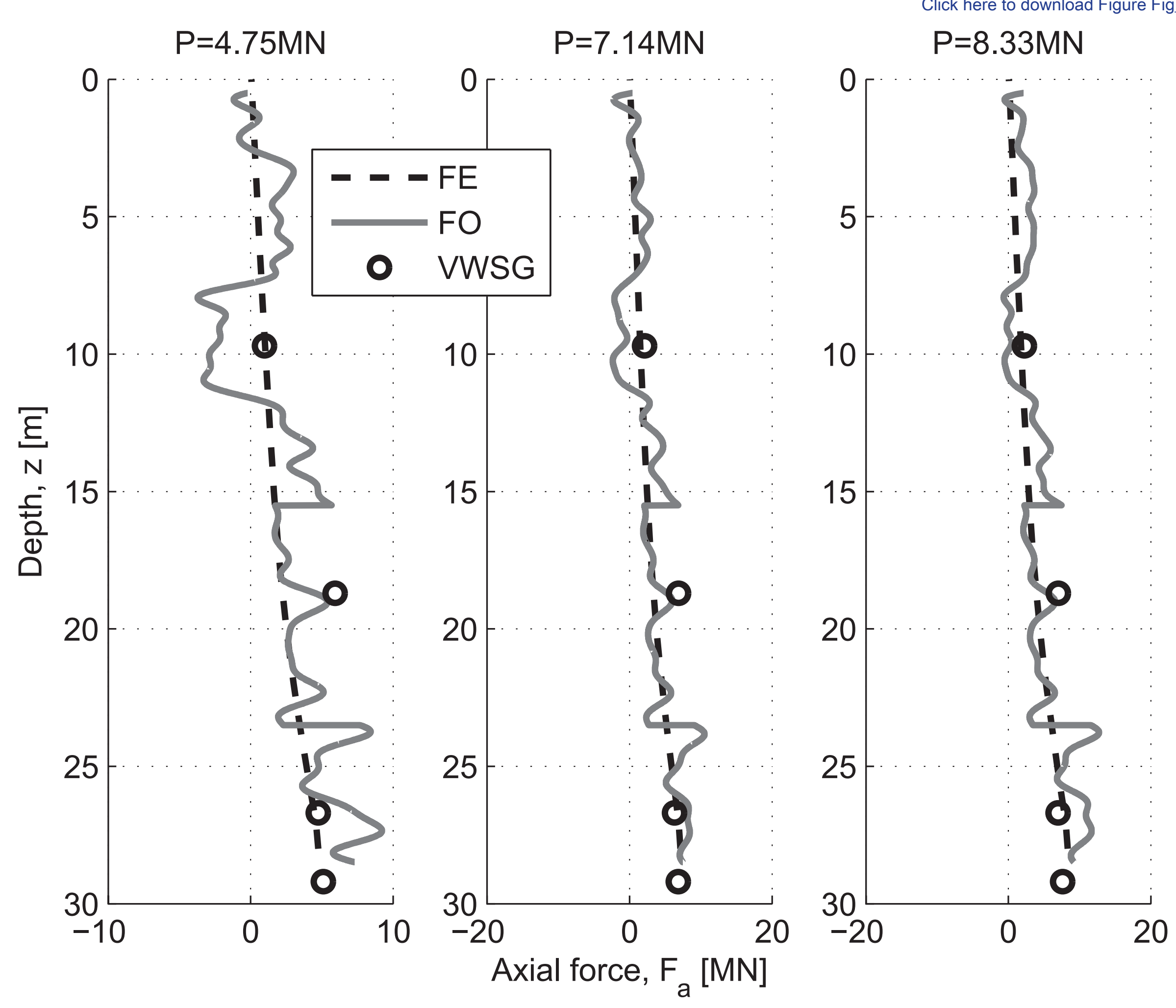



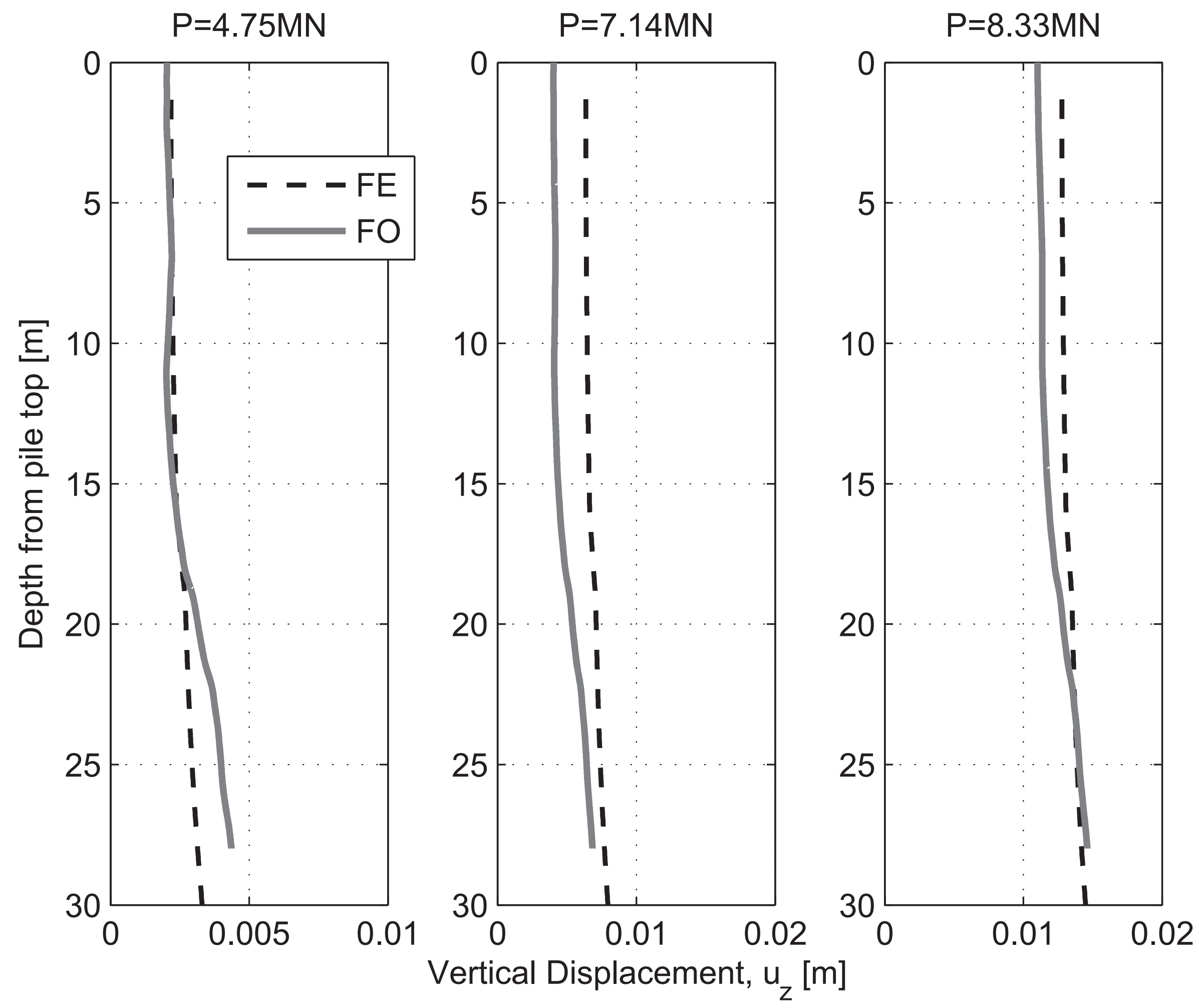

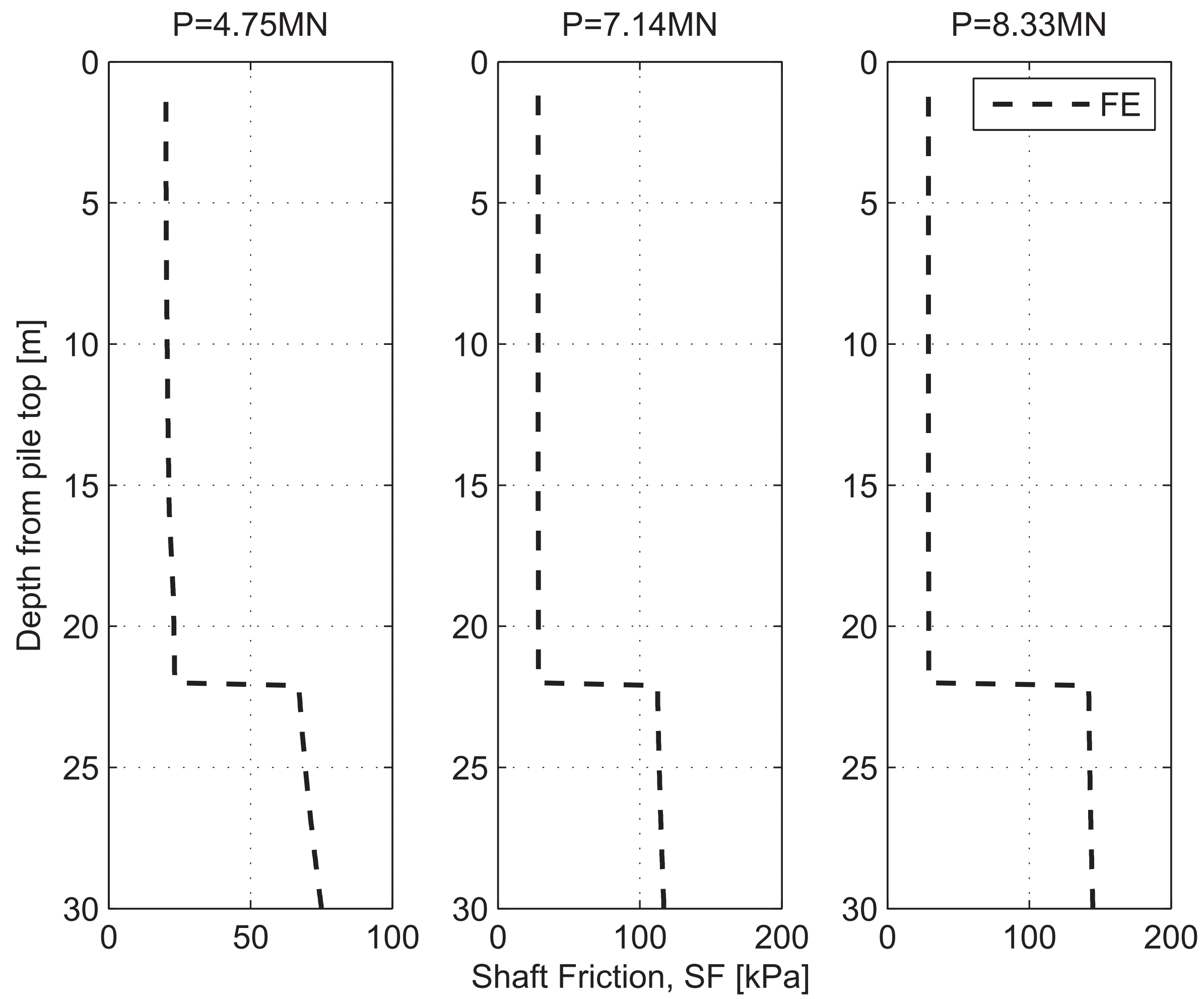
Click here to download Figure Fig_13b.eps $\stackrel{ \pm}{*}$

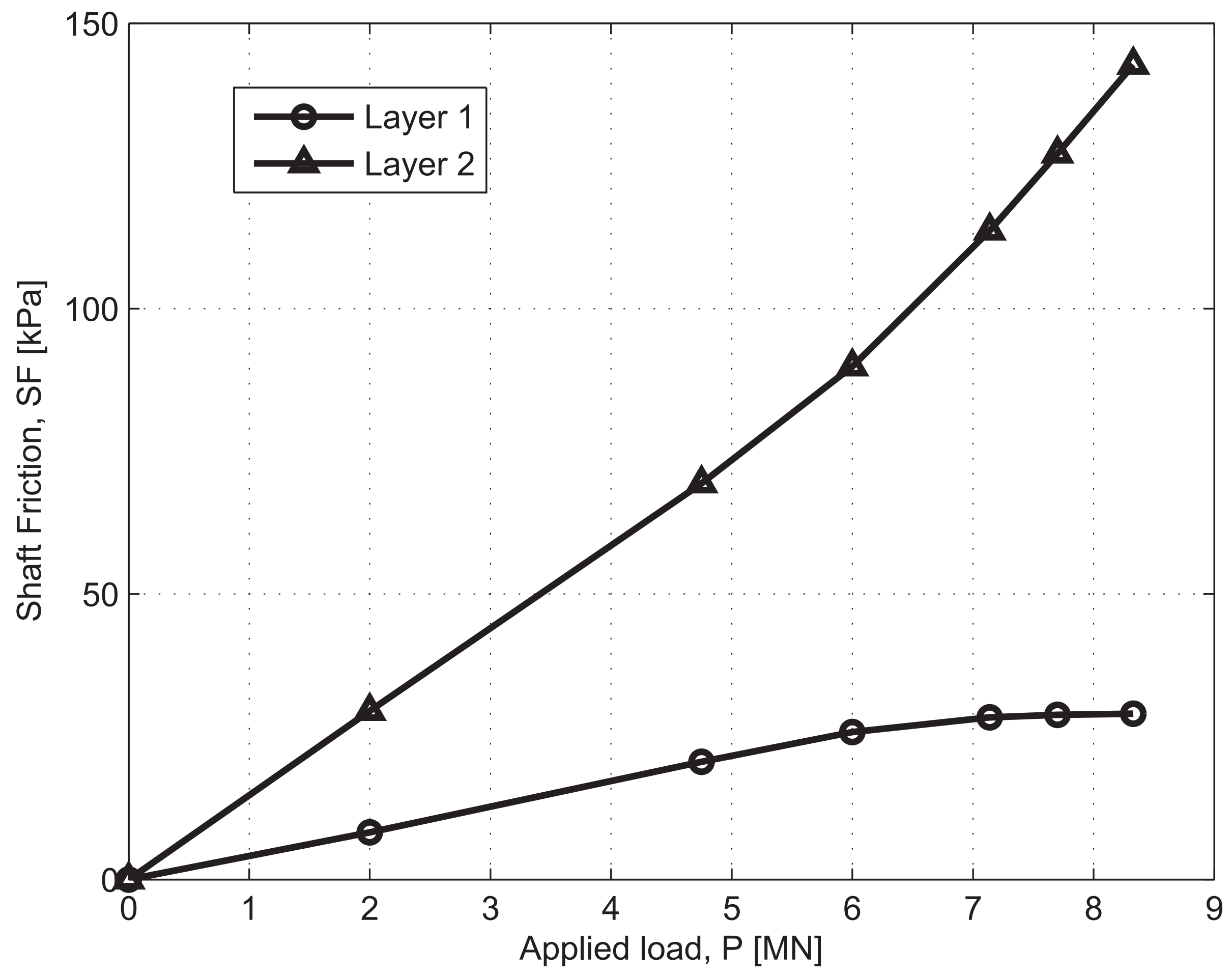


Click here to download Figure Fig_13c.eps $\stackrel{ \pm}{*}$

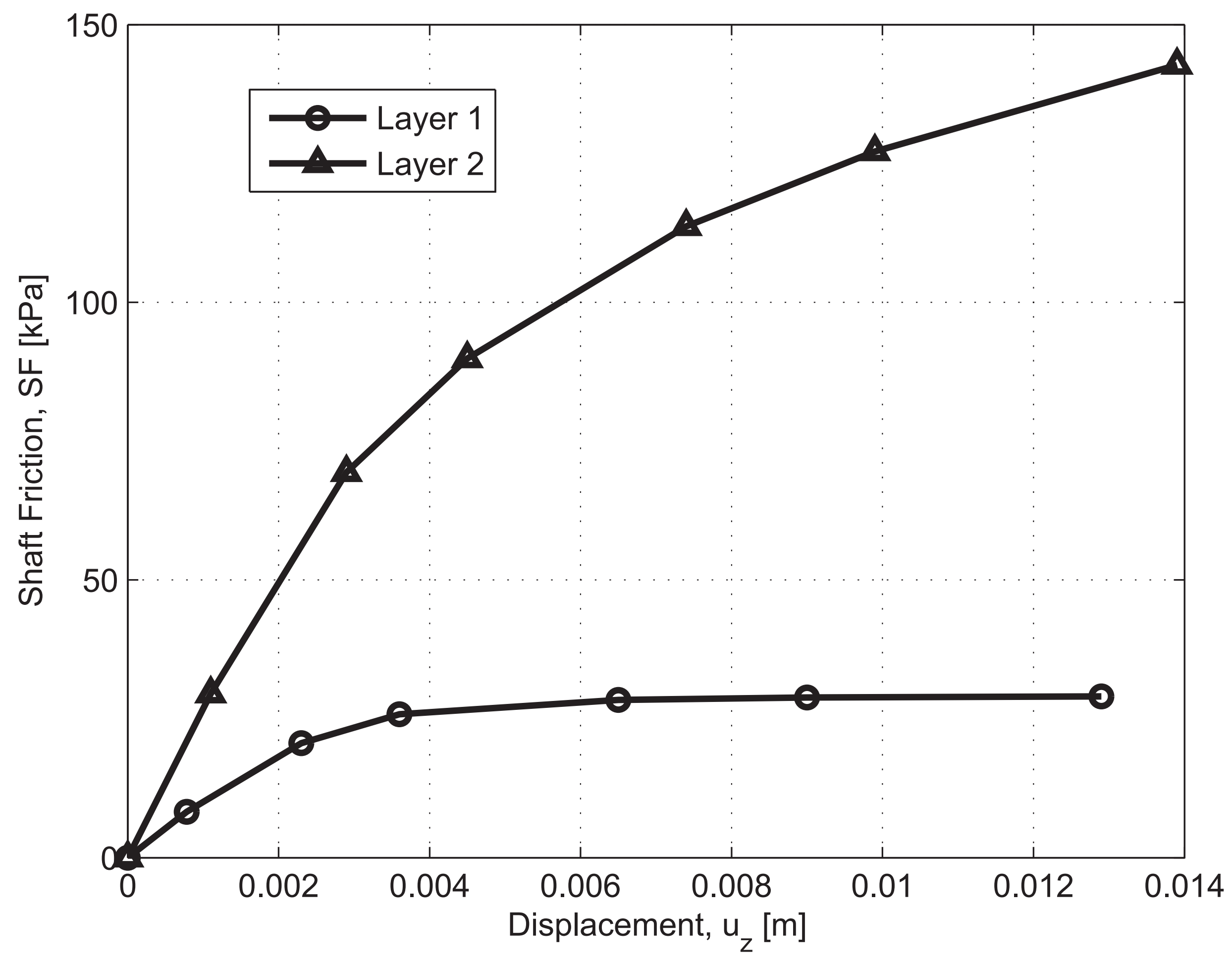


Click here to download Figure Fig_13d.eps $\stackrel{ \pm}{*}$

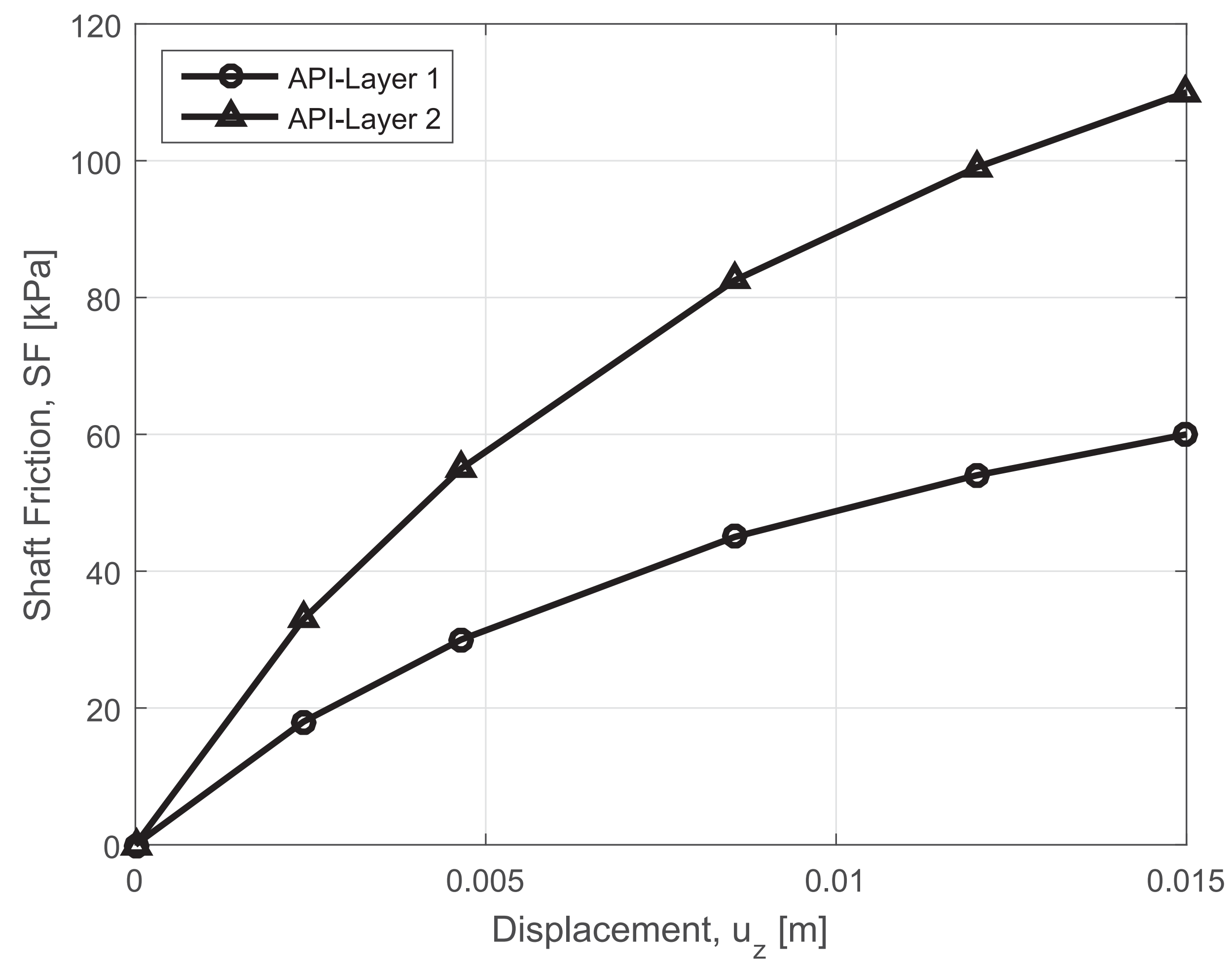



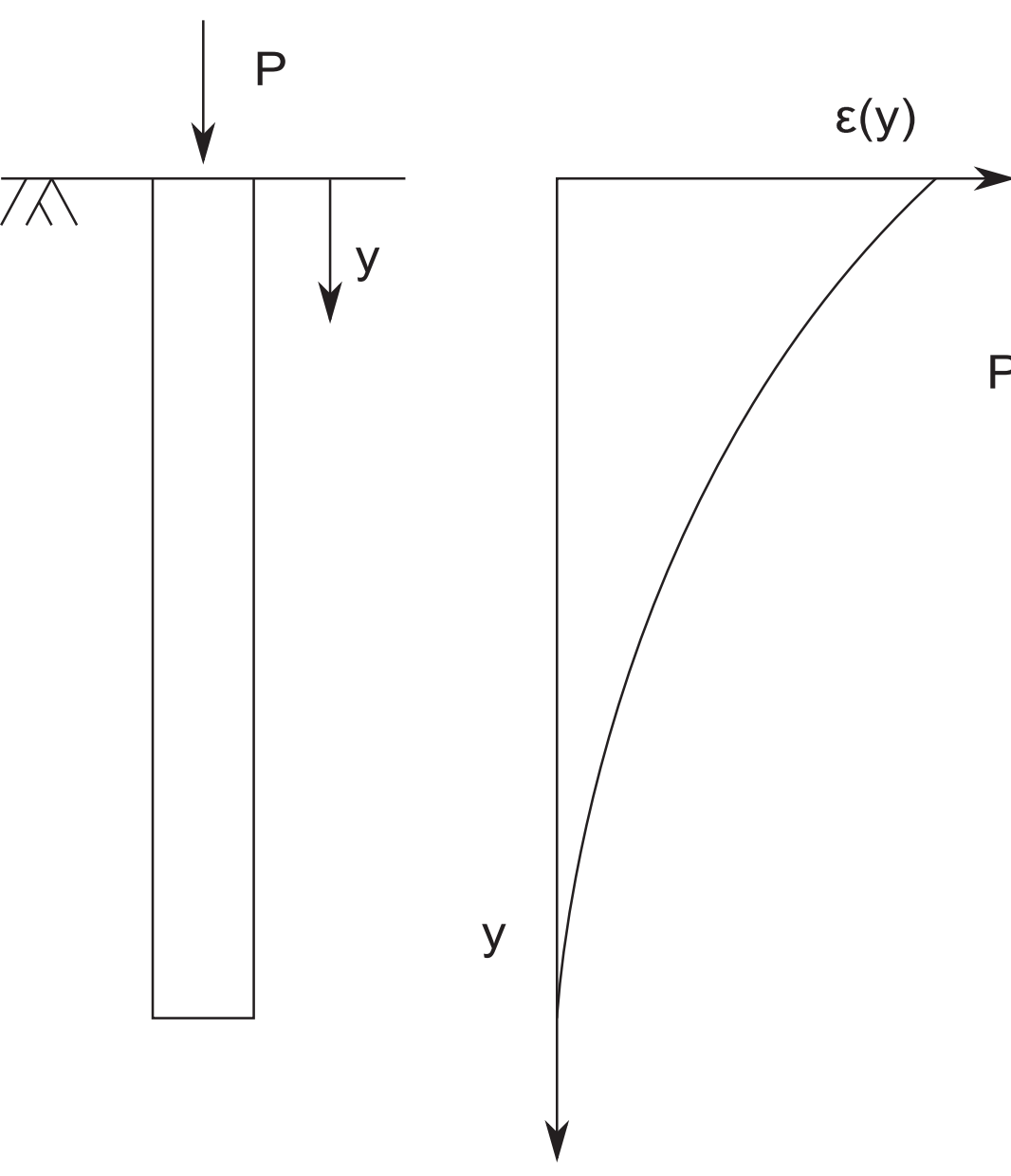

(a) (b)

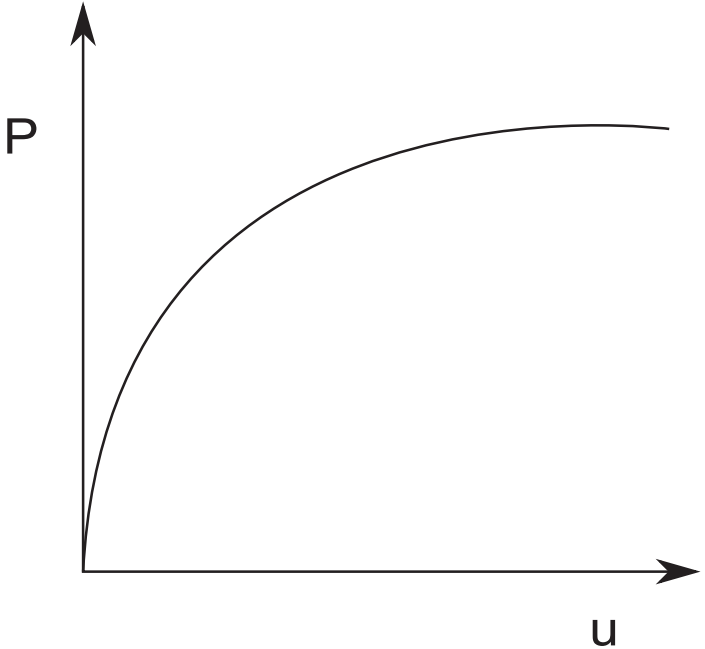

(c)

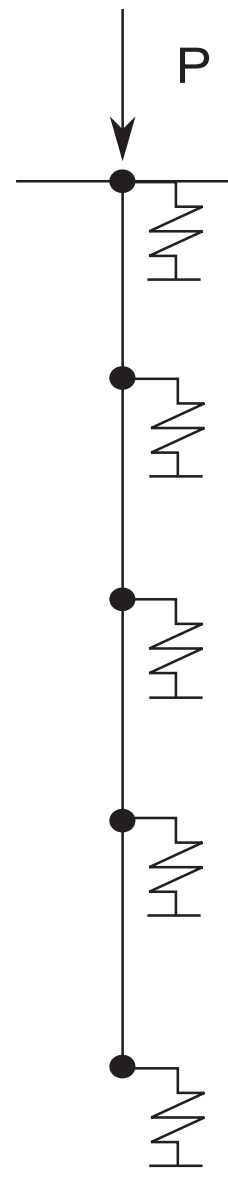

(d)

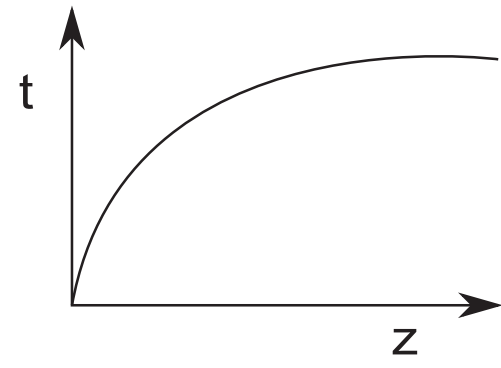

(e) 